\title{
Benthic chamber and profiling landers in oceanography - A review of design, technical solutions and functioning
}

A. Tengberg', F. De Bovee'², P. Hall', W. Berelson 3 , D. Chadwick ${ }^{4}$, G. Ciceris ${ }^{3}$, P. Crassous 6 ,

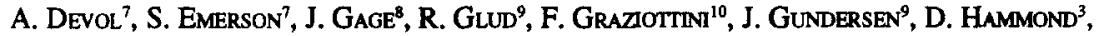

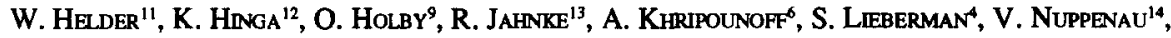
O. PfanNKuChe ${ }^{15}$, C. Reimers ${ }^{16}$, G. Rowe ${ }^{17}$, A. SAHAM ${ }^{18}$, F. SAyles ${ }^{19}$, M. SchurTeR ${ }^{20}$, D. SMallman ${ }^{8}$, B. Wehri ${ }^{20}$ and P. De WILDE"

'Dept. of Analytical and Marine Chemistry, University of Goteborg and Chalmers University of Technology, S-41296 Göteborg, Sweden

${ }^{2}$ Observatoire Océanologique de Banyuls, Laboratoire Arago, CNRS URA 117, F-66650 Banyuls-sur-mer, France

${ }^{3}$ Dept. of Earth Sciences, University of Southern California, Los Angeles, CA 90089-0740, USA ${ }^{4}$ Naval Command, Control and Ocean Surveillance Center, RDTE Division, 53560 Hull Street, San Diego, CA 92152-5001, USA

${ }^{5}$ CISE S.p.A., Via Reggio Emilia 39, 1-20090 Segrate (Mi), Italy

'IFREMER, Centre de Brest, BP 70, F-29263 Plouzané, France

${ }^{7}$ School of Oceanography, WB-10, University of Washington, Seattle, WA 98195, USA

${ }^{8}$ Dunstaffnage Marine Laboratory, P. O. Box 3, Oban, Argyll, PA34 4AD, UK

${ }^{\circ}$ Max Planck Institute for Marine Microbiology, Fahrenheitstr. 1, D-28359 Bremen 33, Germany

${ }^{10}$ IDRONAUT, Via Monte Amiata 10, 1-20047 Brugherio (Mi), Italy

${ }^{I I}$ Netherlands Institute for Sea Research, P.O. Box 59, 1790 AB Den Burg, Texel, The Netherlands

${ }^{12}$ Graduate School of Oceanography, University of Rhode Island, Narragansett Bay Campus, Narragansett, RI 02882-1197, USA

${ }^{13}$ Skidaway Institute of Oceanography, P.O. Box 13687, Savannah, GA 31416, USA

${ }^{14}$ Institut für Hydrobiologie und Fishereiwissenschafi, Universitat Hamburg, Zeiseweg 9, D-22765 Hamburg, Germany

${ }^{15}$ Forschungszentrum für Marine Geowissenschaften der Christian-Albrechts-Universitat zu Kiel, GEOMAR, Wischhofstrasse 1-3, D-24148 Kiel, Germany

${ }^{16}$ Institute of Marine and Coastal Sciences, Rutgers University, New Brunswick, NJ 08903-0231, USA

${ }^{17}$ Dept. of Oceanography, Texas A\&M University, College station, TX 77840, USA

${ }^{18}$ Dept. of Oceanography, University of British Columbia, 6270 University Boulevard, Vancouver, B.C., Canada V6T IZ4

${ }^{19}$ Dept. of Marine Chemistry and Geochemistry, Woods Hole Oceanographic Institution, Woods Hole, MA 02543, USA

${ }^{20}$ Swiss Federal Institute of Environmental Science and Technology (EAWAG), CH-6047 Kastanienbaum, Switzerland

Abstract - We review and evaluate the design and operation of twenty-seven known autonomous benthic chamber and profiling lander instruments. We have made a detailed comparison of the different existing lander designs and discuss the relative strengths and weaknesses of each. Every aspect of a lander deployment, from preparation and launch to recovery and sample treatment is presented and compared. It is our intention that this publication will make it easier for future lander builders to choose a design suitable for their needs and to avoid unnecessary mistakes. 


\section{CONTENTS}

1. Introduction 254

2. History of chamber incubating and profiling sea-floor landers 255

2.1. Different types of instruments for sea-floor investigations 255

2.2. History and presentation of chamber incubating instruments 256

2.3. History and presentation of profiling landers 257

3. Material choices for lander frames and preparation before launching 262

4. Descent and landing 263

$\begin{array}{ll}\text { 4.1. Descent } & 263\end{array}$

4.2. Ballast weights 266

$\begin{array}{ll}\text { 4.3. Landing } & 266\end{array}$

5. Implantation in sediment of chamber and profiling instruments 267

6. Bottom deployment 270

$\begin{array}{ll}\text { 6.1. Profiling landers } & 270\end{array}$

6.2. Chamber landers: chamber design, surface area and 272 number of chambers

$\begin{array}{ll}\text { 6.3. Chamber materials and lid closing } & 272\end{array}$

$\begin{array}{ll}\text { 6.4. Chamber stirring } & 273\end{array}$

6.5. Microprocessors and lander electronics 276

$\begin{array}{ll}\text { 6.6. Water sampling } & 277\end{array}$

6.7. Pore water and sediment sampling 279

$\begin{array}{ll}\text { 6.8. In-situ measurements with chamber landers } & 279\end{array}$

6.9. Other equipment 282

$\begin{array}{ll}\text { 6.10. Electric energy } & 283\end{array}$

7. Ascent and recovery 283

8. Perspectives and remaining tasks 285

9. Acknowledgements 290

10. References 290

\section{INTRODUCTION}

The sea floor plays an important role in the regulation of the chemical composition of water masses in the oceans. Processes in sediments are important links or sinks in the biogeochemical cycles of elements in aquatic systems. In addition the seabed is the habitat for a great variety of higher organisms, and as such constitutes a distinct stratum for benthic life and consequently for numerous biological processes. The conventional approach to study these geochemical and biological processes is to collect a sediment sample from the sea-bed bring it up to the surface and there make observations and carry out experiments on it either on-board ship or in the laboratory. Methods that have been used to evaluate biogeochemical activity in sediments and at the sedimentwater interface include direct measurements of benthic fluxes during incubations of sediment together with overlying water, and measurements of solute distributions in and above sediments. The latter have been achieved both in-situ and ex-situ either directly using of microelectrodes or by analyses of porewaters extracted from the sediment. Gradients solutes in porewaters have often been used to calculate solute fluxes within sediments and across the sediment-water interface (for recent reviews of these topics see e.g. SANTSCHI, HÖHENER, BENOIT and BUCHHOLTZ-TEN BRINK (1990) and DE LANGE, CRANSTON, HYDES and BOUST (1992).

Accurate data are difficult if not impossible to obtain from the deep-sea, because artefacts are induced when the samples are subjected to large changes in hydrostatic pressure and (often) temperature as they are brought up to the surface. It is therefore preferable to carry out experiments and measurements directly at the sea floor (in-situ). Even when working at quite shallow depths 
in shelf seas there is general agreement that it is preferable, if possible, to carry out experiments in-situ, to avoid artefacts caused by excessive disturbance. Such studies can be carried out using benthic landers or other instruments deployed on the sea-floor. When designing and using these instruments an important goal is to minimise the disturbance they cause to the sea-bed both during landing and operation. An additional benefit of using landers for deep sea-floor studies is that, when they work properly, they are less demanding of ship time (and thus of money) than conventional sediment coring techniques. Once the lander has been deployed the ship is free to undertake other operations after, until it is time for recovery.

When designing a lander there are numerous points that need to be considered if it is to be successful in achieving its designated tasks at the sea-floor. These include the methods of launching and recovery, the choice of construction materials for various components, the design, descent and ascent speeds, the landing technique, selection of the techniques for sampling, observation and measurement, and the choice of electronics and energy requirements.

Some brief reviews of benthic chambers/microcosms (ZEITZSCHEL and DAVIS, 1978; LALLI, 1990) and chamber lander techniques (BERELSON, HAMMOND, SMITH, JAHNKE, DEVOL, HINGA, ROWE and SAYLES, 1987; JAHNKE AND CHRISTIANSEN, 1989) have already been published. These comparisons presented successful results for some projects, whereas to our knowledge no reports have previously been published on technical problems encountered when designing and deploying autonomous devices. Moreover since these earlier reviews were published, several new lander systems have been constructed (or are under construction) and the concept of profiling landers is new. In this paper we will describe the various benthic flux chamber and pore water profiling lander instruments that have been constructed to date and discuss their relative strengths and weaknesses.

\section{HISTORY OF CHAMBER INCUBATING AND PROFILING SEA-FLOOR LANDERS}

\subsection{Different types of instruments for sea-floor investigations}

"Lander" is a general term for any autonomous, unmanned oceanographic research vehicle that free-falls to the sea-floor unattached to any cable, and then operates independently on the sea-floor. At the end of the deployment, ballast weights are released either by a pre-programmed timing device or on an acoustic command transmitted from the surface. The lander then floats back up to the surface by virtue of its positive buoyancy. Other terms that have been used for such devises are "Free-fall vehicle" and "Pop-up vehicle". There are many examples which can be cited of such instruments which have been used for a wide variety of applications. Landers have been used to study nepheloid layers (e.g. VANGRIESHEIM and KHRIPOUNOFF, 1990), for fine-scale, highresolution sampling of water in the benthic boundary layer (e.g. THOMSEN, GRAF, MARTENS and STEEN, 1994), for long term measurements of near bottom currents, tides (e.g. SPENCER, VODEN and VASSIE, 1994), or microseismic activity (e.g. KIRK, LANGFORD and WHITMARSH, 1982). Other applications are autonomous instruments for tracking deep-sea fishes and estimating their abundances (e.g. ARMSTRONG, BAGLEY and PRIEDE, 1992), and time-lapse photography of the sea-bed activity (e.g. ISAACS and SCHWARTZLOZE, 1975; BILLETT, LAMPITT, RICE and MANTOURA, 1983; RICE, THURSTON and BETT, 1994). An interesting, although non-autonomous technique, has been to place a large video-controlled chamber over the top of deep-sea vents from a conventional surface research vessel (LINKE, SUESS, TORRES, MARTENS, RUGH, ZIEBIS and KULM, 1994). This chamber isolates, collects and measures fluid flow from cold seeps, and eliminates the need for (and costs of) deployment by submersible. Another autonomous lander for geophysical studies of the 
sea-floor using mainly a magnetic recorder and geophones has been developed by E. A. KONTAR (Shirshov Inst. of Oceanology, Moscow, pers. comm.).

During the "European Benthic Lander Research and Technology Workshop" (Bremen, November 1993) the need was identified to be able to conduct longer-term (up to one year) lander deployments in an area. However, if such an instrument were to be left continuously throughout the deployment on exactly the same site, it will, by its very presence, interfere and alter the natural conditions; so the instrument musteither move or be moved. This can either be solved by recovering and redeploying one or several landers, or by the lander having an autonomous ability to change its location. Such an autonomously mobile instrument ("bottom crawler") is under development at Scripps Institution of Oceanography by K.L. SMITH.

The instruments mentioned above are considered to be outside the scope of this paper and will not be discussed further. This discussion will focus on landers used as platforms which either support benthic chambers or profiling instruments. A chamber lander isolates an area of the seafloor and its overlying water in one or more chambers in order to measure the rates of biogeochemical processes. A profiling lander is equipped with probes that are inserted into the seafloor sediment to measure profiles of water properties above, at and in the pore waters beneath the sediment-water interface.

\subsection{History and presentation of chamber incubating instruments}

The first in-situ experiments on the sea-bed were carried out by scuba divers. Fluxes into or out of sediments have been obtained for a number of substances, by deploying a chamber on the sea floor isolating an area of sediment surface and the overlying water, and then drawing discrete samples at specific times intervals for analysis in the laboratory (e.g. HALLBERG, BÁGANDER, ENGVALl and SHIPPEL, 1972; NIXON, OVIATT and HALE, 1976; HAMMOND, SIMPSON and MATHIEU, 1977; BALZER, 1978; CALLENDER and HAMMOND, 1982; HALL, 1984; RUTGERS VAN DER LOEFF, ANDERSON, HALL, IVERFELDT, JOSEFSON, SUNDBY and WESTERLUND, 1984). In the latter two reports constant oxygen concentration were maintained in the overlying water. Extending the use of this type of chamber to depths beyond the range of scuba divers has been possible either by using a wire, a mooring, or a submersible (e.g. PAMATMAT and FENTON, 1968; PAMATMAT and BANSE, 1969; SMTH and TEAL, 1973; ALLER, HALL and RUDE, 1987).

However, using a chamber attached to a surface buoy makes it sensitive to the weather and sea conditions at the surface. Another problem is that a moored lander is vulnerable to fishing activity. The fate of several such moorings has been to be trawled away. The ideal approach would seem to be to deploy landers from submersibles, However, since number of scientific manned submersibles in the world has always been, and is likely to remain limited, for most experiments the use of submersibles for such deployments is impractical nor is it generally affordable. So the development of autonomous free-vehicle landers is one obvious solution to solving these practical difficulties.

The first steps towards development of successful autonomous vehicles were taken in the 1970's by the construction of the FVR (SMITH, CLIFFORD, ELIASON, WALDEN, ROWE and TEAL, 1976), the MANOP Lander (WEISS, KIRSTEN and ACKERMAN, 1977; KIRSTEN and JAHNKE, 1985) and the FVGR-1 (SMTTH, 1978; SMITH, WHITE and LAVER, 1979). The HINGA chamber lander (HINGA, SIEBURTH and HEATH, 1979) was designed to be deployed at the bottom of a mooring. Based on the combined experience gained with these early devices, a number of other landers were developed during the 1980's. The DEVOL lander (DEVOL, 1987; DEVOL and CHRISTENSEN, 1993) is similar to the FVR, and the IHF lander (PFANNKUCHE, 1992; 1993) resembles the FVGR-1. The USC landers (BERELSON and HAMMOND, 1986) were developed as a result of the need to have a 
device capable of making multiple flux incubations with a short turn-round, and of being deployed in a wide range of environments. The development of the BECI (JAHNKE and CHRISTLANSEN, 1989) was based on the philosophy of keeping the concept as simple as possible, in reaction to the adverse experiences gained during the development of the highly complex MANOP lander. There was now third generation of landers which involved various new developments including FVGR-2 (based on FVR and FVGR-1) (SMITH, 1987), and the GOMEX lander (ROWE, BOLAND, PHOEL, ANDERSON and BISCA YE, 1995) which was designed not only to estimate fluxes but also to attract and capture benthic organisms.

Another further generation of benthic chamber landers has been designed during the 1990's, some of which are still under construction. The most complex of these is ROLAI ${ }^{2} D$ (SAYLES and DICKINSON, 1991; DICKINSON, WAYNE and SAYLES, 1992), which has the highest capacity for replicating sampling and measurement tasks during a single deployment. It is also the only lander capable of deployments of up to 50 days. BOLAS (Table 1) is equipped with new systems for sampling water and sediment, and is also equipped with a camera to photograph benthic organisms inside the chambers. The design of ELINOR (GLUD, GUNDERSEN, JÆRGENSEN, REVSBECH and HÜETTEL, 1995) was based on $B E C I$ and equipped with a novel type of microelectrode probe. ITO is another chamber lander based on the $B E C I$ concept and has been constructed in Japan. RAP 2, a further development of $R A P 1$, is the only lander equipped with a parachute to ensure a gentle landing. Two chamber landers of similar construction with "multiple corer type" sediment sampling systems are the BANYULS and the GÖTEBORG landers (DE BOVEE, TENGBERG, HALL, BARBOUTY, LE BELLER, BRILLOIT and LANDEN, 1995). The IDRONAUT/CISEchamber(BARBANTI, BONIFORTI, CICERI, MARTINOTTI and VIRTANEN, 1992; CICERI, MARAN, MARTINOTTI and QUEIRAZZA, 1992) has a special system to maintain oxygen and $\mathrm{pH}$ levels constant inside the chamber during the incubations. The same system for maintaining oxygen concentrations is used on the Benthic Flux Sampling Device (BFSD) developed by CHADWICK, STANLEY and LIEBERMAN (1993). The EAWAG chamber instrument (WEHRLI, DINKEL and URBAN, 1994), which is not autonomous, has, like the IDRONAUT/CISE chamber, been successfully operated in freshwater. The BIO-C-FLUX and BIOSTABLE landers (Table 1) became operational during 1994, the latter being equipped with an advanced video-system.

\subsection{History and presentation of profiling landers}

An alternative approach to quantifying benthic exchange processes in-situ is to use sediment profiling instruments utilising mini- or microelectrodes to make precision measurements of chemical profiles and then to interpret the results with mathematical models. REIMERS (1987) developed the first autonomous instrument of this type and inspired the development of several similar instruments like the UW PROFILER (ARCHER, EMERSON and SMTTH, 1989a; ARCHER, EMERSON and REIMERS, 1989b; HALES, EMERSON and ARCHER, 1994), PROFILUREN (GUNDERSEN and JøRGENSEN, 1990; GUNDERSEN and JøRGENSEN, 1991; GUNDERSEN, JøRGENSEN, LARSEN and JANNASCH, 1992) and TROL (EPPING and HELDER, 1995). A third generation of these instruments includes BOTTY and the GEOMAR profiler (Table 1) which were inspired by TROL. Reimers has continued to develop two further profiling landers (REIMERS, JAHNKE and MCCORKLE, 1992; CAI and REIMERS, 1993; REIMERS, unpublished results). These, together with the $U W$ profiler which has fibre optical sensors, are the only instruments presently capable of measuring in-situ $\mathrm{pCO}_{2}$ profiles in sediments. The SAHAMI profiler (Table 1) is a low-cost profiling instrument, specially developed to measure oxygen uptake by polluted sediments, which, although it is a non-autonomous instrument, is included in this paper. 


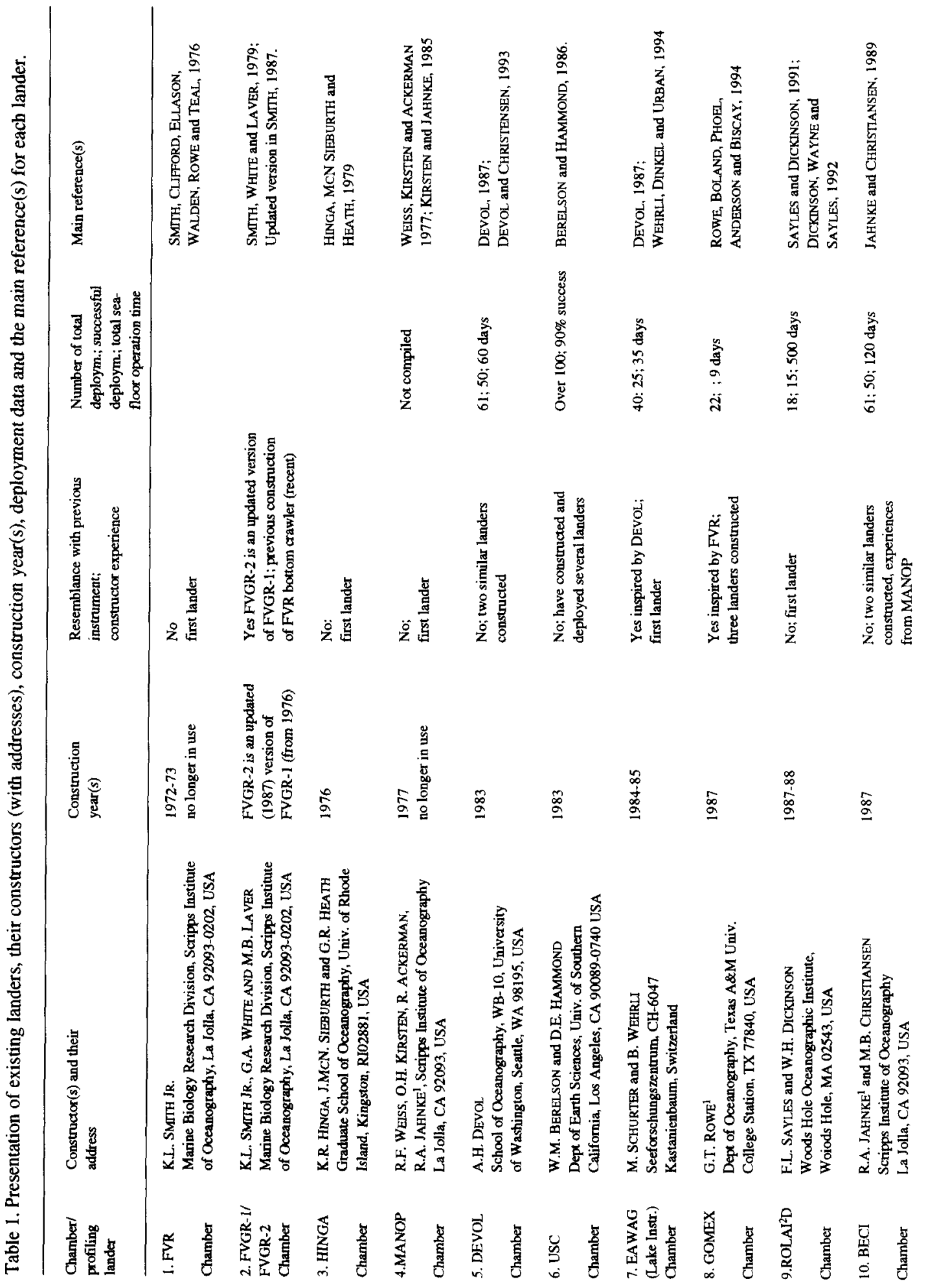




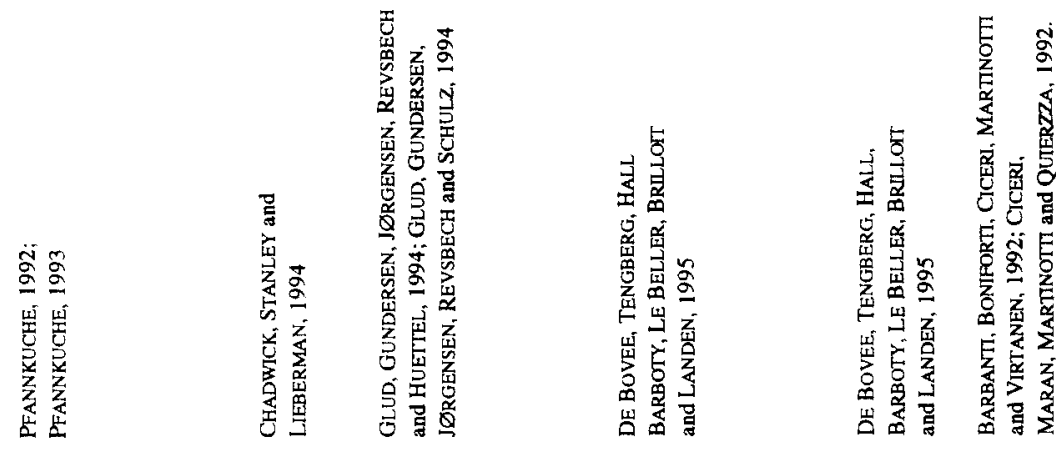

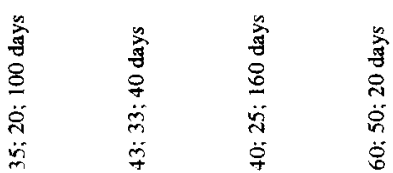

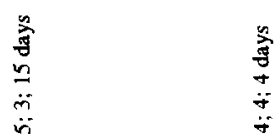

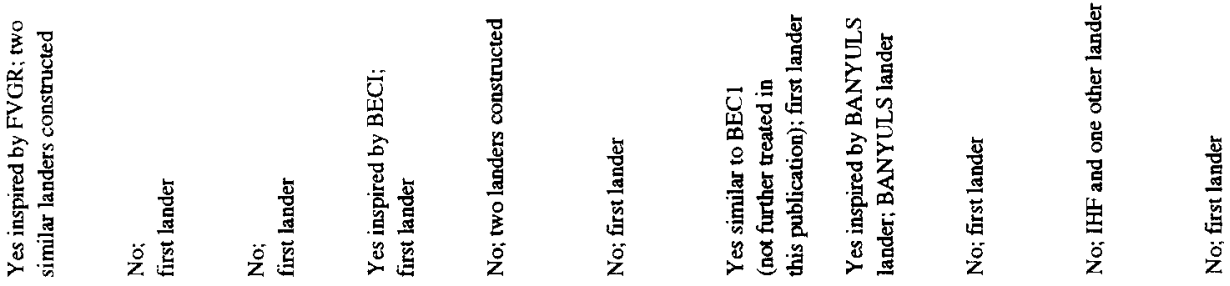

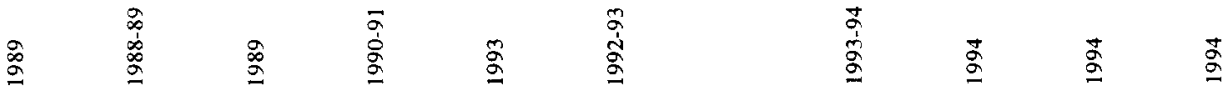

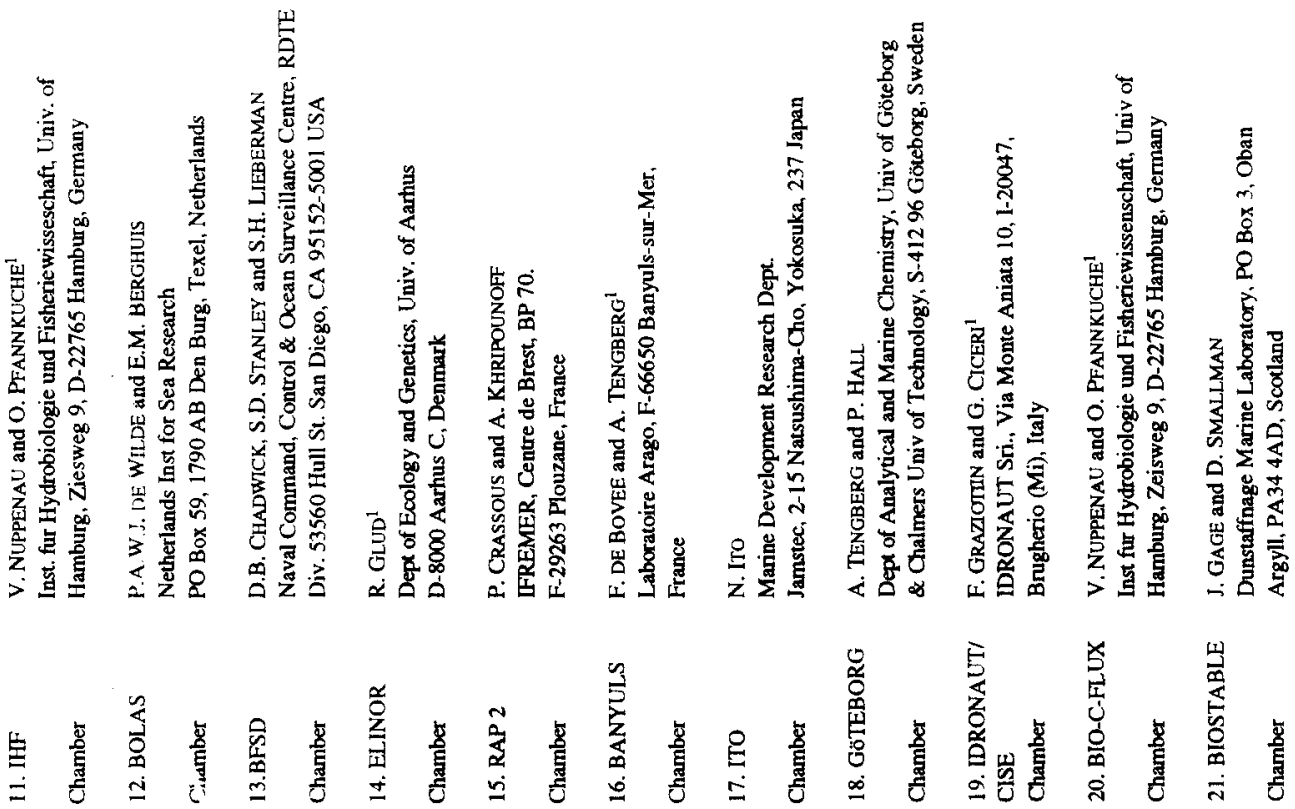



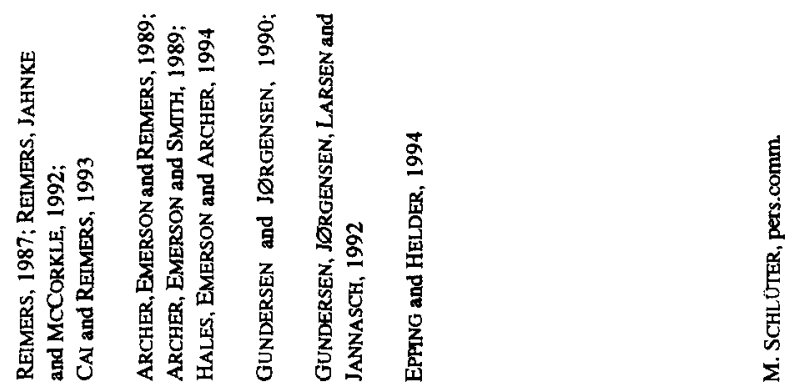

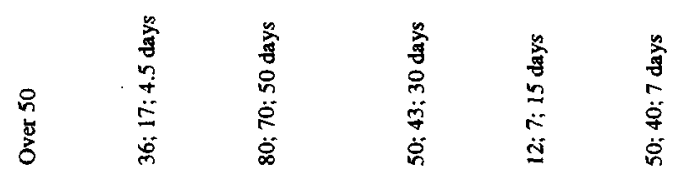

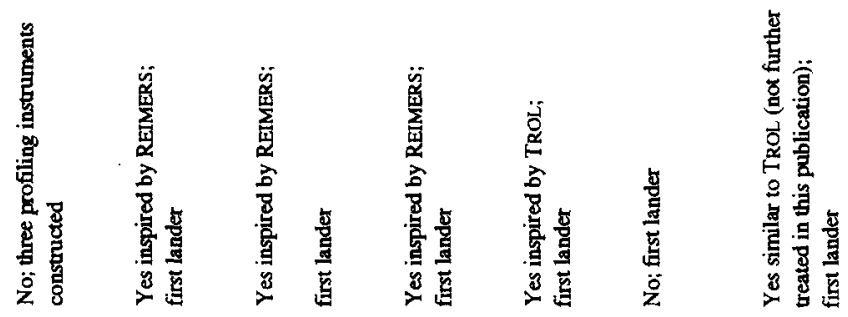

\&.

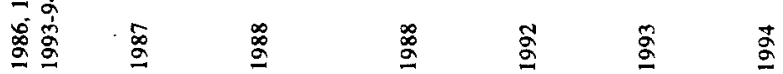

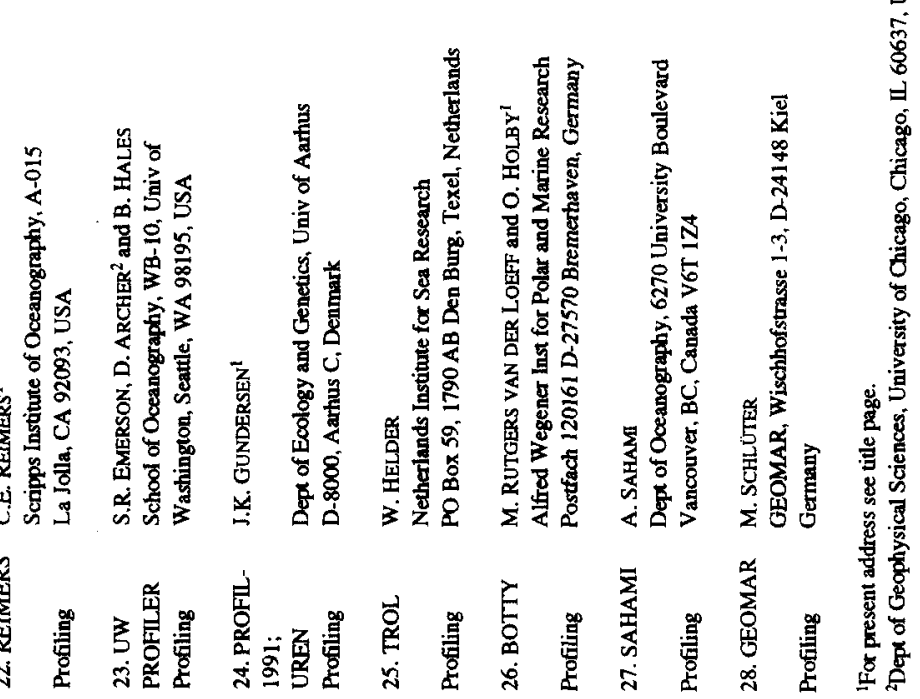





\section{MATERIAL CHOICES FOR LANDER FRAMES AND PREPARATION BEFORE LAUNCHING}

An autonomous benthic lander must have a basic support frame on which is mounted the instruments, the ballast weights, the release mechanism and the buoyancy. The main objective when constructing this frame is to keep its weight as low as possible without compromising its mechanical strength. Keeping the weight low not only makes the whole instrument easier to handle, but also minimises the need for expensive buoyancy material (cf. Ascension and recovery). While deployed the lander and its frame are exposed to relatively trivial static stresses, so the main risks of mechanical damage occur during launch and recovery.

For ease of transport and storage, particularly in containers, most constructors have designed outer frames which are readily dismantled. The material most commonly used is aluminium (Table 2 ), which has the advantages of being relatively inexpensive and light $\left(\rho_{\mathrm{Al}}=2600-2850 \mathrm{~kg} / \mathrm{m}^{3}\right.$ depending on the alloy chosen). However, aluminium is not as strong as some other materials, for example stainless steel, and many ships do not carry the special welding equipment required for repairs.

Alternative materials for frames are stainless steel, titanium and composite materials such as glass fibre reinforced with aramid fibre (commonly called Kevlar(C) and with epoxy resin as binding material.

Stainless steel $\left(\rho_{\text {stainless }}=7950 \mathrm{~kg} / \mathrm{m}^{3}\right)$ is about three times denser than aluminium and at least four times denser than the composite materials $\left(\rho_{\text {composite }}=1500 \mathrm{~kg} / \mathrm{m}^{3}\right)$. Titanium has a density of $\rho_{\text {titanium }}=4500 \mathrm{~kg} / \mathrm{m}^{3}$. The greater weight of stainless steel is compensated for by its better mechanical properties. It has an E-module (the elasticity module $E$ is commonly used in mechanics as a measure of strength, e.g. bending strength) which is almost three times higher than for aluminium and about one and a half time higher than for composite materials; $\mathbf{E}_{\text {stainless }}=210 \mathrm{GPa}$ compared to $\mathbf{E}_{\mathrm{Al}}=70 \mathrm{GPa}, \mathbf{E}_{\text {composite }}=120-140 \mathrm{GPa}$ and $\mathbf{E}_{\text {titanium }}=114-118 \mathrm{GPa}$.

The highest costs incurred while constructing a lander are the labour costs. But if materials for the frame have to be chosen on the basis of cost, costs of aluminium and stainless steel will be similar, whereas titanium and composite materials will be roughly 20 times more expensive (at 1994 prices). The cost of composite material depends on the quantities of aramid fibres used; using more aramid fibres increases both the mechanical strength and the costs.

If aluminium or stainless steel are to be used the choices of alloys to be used has to be governed by which are the most resistant to corrosion in sea-water. The best choices are, for stainless steel AA 316 (US standard norm), and for aluminium AA 5052, AA 5754, AA 5083, AA 6082, AA 6063 and AA 6061 (US standard norm). So far composites have not been used, in spite of their lower weight and better mechanical properties, because their behaviour under high pressure is poorly known, and the special equipment (oven and vacuum pump) required for fabrication and repair.

Titanium is relatively light and strong, but is difficult to weld and to polish. Good quality titanium welding requires special precautions, and industrial welding is undertaken in an oxygen frée environment, such as an argon filled tent, using specialist welding equipment. Polishing titanium has to be undertaken with considerable caution because titanium dust can ignite spontaneously. There are many different qualities of titanium to choose from but those which are brittle should be avoided.

Galvanised steel is a less favoured alternative although it has the similar mechanical and physical properties to stainless steel and is about half the price. It has several disadvantages. Careful attention has to be given to the shape of the frame since "closed" sections (e.g. cylindrical tubes) are difficult to galvanise internally leaving them vulnerable to corrosion, and any disruption to the protective layer through modifications or damage to the rig will set off corrosion immediately. Whatever 
material is chosen most constructors recommend the use of sacrificial anodes (made of $\mathrm{Zn}$ or $\mathrm{Mg}$ ) to reduce the corrosion problems.

Regardless of the metal(s) used in constructing the frame, considerable care has to be taken if any combination of different metals is used (e.g. stainless steel bolts in an aluminium frame, titanium pressure house in a stainless steel frame). Failure to insulate the metals from one another, by coating or painting, will result in the rapid corrosion of the metal with the lower reduction potential.

\section{DESCENT AND LANDING}

\subsection{Descent}

Currents within the oceanic water column will affect a lander during its descent and ascent, and may carry it away from the desired position (HENDRICKS and RODENBUSH, 1981; NABATOV and RAZZHIVIN, 1986). The faster a lander sinks or rises the less it will drift out of position, rates of ca $0.5-1 \mathrm{~ms}^{-1}$ are acceptable, but this still means that a lander will take 1-2 hours to traverse a water column 3,600m deep. Another reason to maximise the descent and ascent rates is to save ship time, by minimising the waiting time after launching and weight release, and if a lander takes too long a time to ascend, there may be problems relocating it at the surface. However, if the lander's descent rate is too fast, it is liable to cause excessive disturbance to the sediment-water interface at the measurement site. Also it will be driven deeper into the sediment and so run the risk of the lander becoming irretrievably stuck in the bottom. Some landers have become trapped temporarily in sticky bottom sediments (e.g. TROL and BOLAS during a Mediterranean cruise in 1990). Pull out forces can be increased by adding more buoyancy but this incurs penalties of increased cost and the need to use more ballast to attain the same descent speed.

A lander sinking through water is affected by the gravitation, the Archimedes principle and the drag force (MORTENSEN and LANGE, 1976). The drag results not only from the friction between the water and the lander frame but also on the water moving with the lander; this water is called added mass (BIRD and MocKROS, 1986).

The use of classical hydrodynamic formulae together with an acceleration that approaches zero, gives the following approximate expression for the speed $\left(\mathrm{V}_{\text {limit }}\right)$ of a free falling irregular body, such as a lander, in water.

$$
v_{\text {limit }}=\sqrt{\frac{2 m_{\text {water }} g}{\rho_{\text {liquid }} C_{D} s}}
$$

The gravity $\left(g=9.81 \mathrm{~ms}^{-2}\right)$ as well as the sea-water density $\left(\rho \approx 1026 \mathrm{kgm}^{-3}\right.$ at surface $)$ are considered to be constant in Eqn 1. Nevertheless, sea water density increases with $1.5-2 \%$ from the surface to a depth of $6,000 \mathrm{~m}$ as a result of compression. SAYLES and DICKINSON (1991) estimated that this increases the positive buoyancy of their lander by about $30 \mathrm{~kg}$ at $4,000 \mathrm{~m}$ depth, whereas KIRSTEN and JAHNKE (1985) concluded that the high hydrostatic pressure compressed the volumes of components of their lander sufficiently to reduce its overall buoyancy. Other users of lander have observed little change in descent or ascent rates with depth, suggesting the pressure effects cancel each other out so that buoyancy changes with depth are negligible.

As shown by Eq.1, lander speed is dependent on the negative (or positive when ascending) buoyancy $\left(m_{\text {water }}=m_{\text {air }}-r V\right.$, where $V$ is the lander volume) and the $C_{D} S$. The $C_{D} S$ can be split 


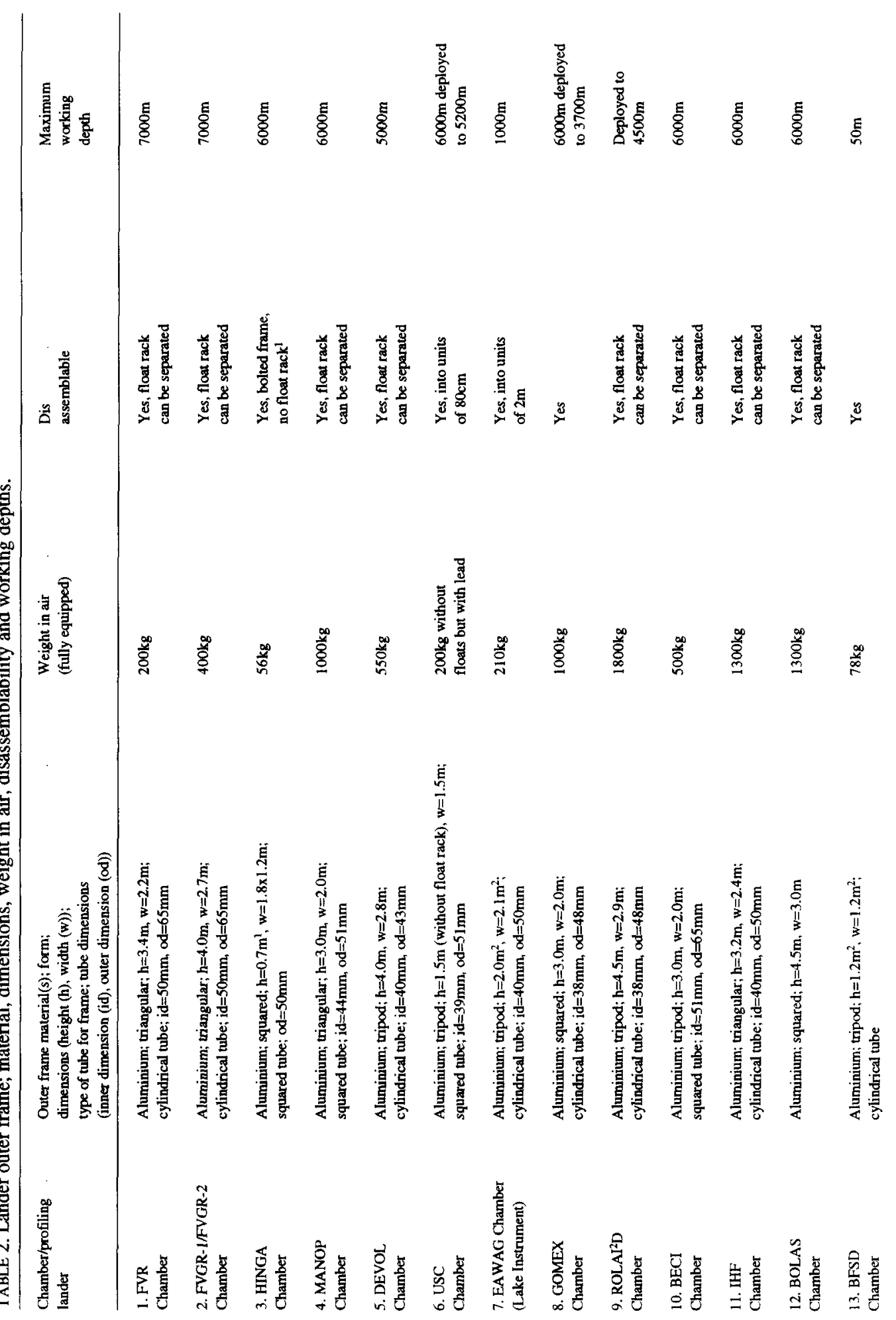




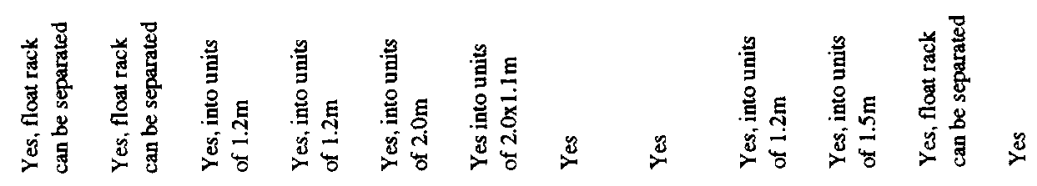

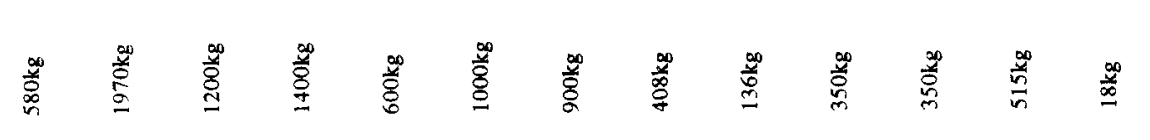

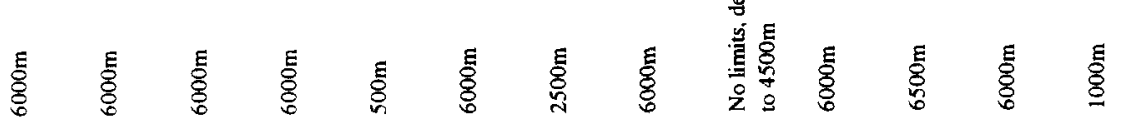

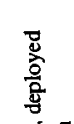


into a projected area term $\left(S\left(\mathrm{~m}^{2}\right)\right)$ and a drag coefficient $\left(\mathrm{C}_{\mathrm{D}}\right.$ (unitless)) that depends on the Reynolds number and the structure's form. $C_{D}$ is different depending on whether the lander is sinking or ascending. For practical reasons and the complex form of a lander, it is usually sufficient to consider the $C_{D}$-value as a constant that may be combined with $S$ (HENDRICKS and RODENBUSH, 1981). The role played by the area and the form of a lander in determining sinking and ascent rates is thus represented in the $\mathrm{C}_{\mathrm{D}} \mathrm{S}$ term.

The descent speeds of the various landers range between $25-60 \mathrm{~m} \mathrm{~min}^{-1}$ depending on their form, surface area $\left(C_{D} S\right)$ and weight in water (see Table 2 and 3 ).

\subsection{Ballast weights}

A wide range of materials are used for the ballast weights including concrete, scrap iron, cast iron and lead. Lead has the highest density, but should be avoided because of its potential environmental impact may be serious. Scrap iron (e.g. railway waste) is cheap and easy to obtain but is awkward to use because of its irregular shape. Iron blocks cast into conical shapes are expensive but serve to minimise disturbance upon landing (e.g. BOLAS). Concrete ballast is best avoided, because of its density is relatively low, and its behaviour in the deep-sea environment is poorly known.

Ballast weights can be fixed underneath the frame and used as foot pads (Table 3). Since most of the sediment suction is applied to the foot pads, dropping them off allows the rest of the lander frame to escape easily to begin the ascent back to the surface. While this method of attaching ballast weights, decreases the risk of a lander becoming stuck in the sediment, is not a complete guarantee of success (c.f. Ascension and recovery). One minor inconvenience of this method is that it complicates the deck handling, since either a special rack is needed, or the lander has to be lifted off the deck to attach the weights.

Another option is to use permanently fixed landing pads and to secure the ballast weights to the frame above the sediment. This is liable to increase the suction forces that must be overcome when the weights are released.

\subsection{Landing}

Most landers work successfully by simply crash-landing on to the bottom at a modest speed, as long as the foot pads are large enough to prevent too deep a penetration of the frame in the sediment. Holes in the foot pads can help to reduce the suction on lift off.

Some landing techniques have been devised to minimise the impact both to reduce disturbance of experimental site and the risks of the lander becoming irretrievably stuck. The $R O L A I^{2} D$ lander has a negative buoyancy of $67 \mathrm{~kg}$ when launched, but by the time it reaches a depth of $4000 \mathrm{~m}$ its buoyancy decreases to about $37 \mathrm{~kg}$ as a result of the increased density of the sea water. There is a $52 \mathrm{~kg}$ weight suspended $10 \mathrm{~m}$ beneath the lander, and when this weight hits the bottom the lander buoyancy becomes positive $(15 \mathrm{~kg}$ ) so that it stops sinking and remains suspended above the bottom. On acoustic command from the surface, the lander is then pulled onto the bottom by a winch of a speed at $3 \mathrm{~m} \mathrm{~min}^{-1}$. Contact with the bottom is sensed, either by a light sensor or a contact switch on the winch, which trigger the release of a package of glass floats with $145 \mathrm{~kg}$ positive buoyancy. The lander then has a negative buoyancy of $130 \mathrm{~kg}$, sufficient to push the motor-driven chambers into the sediment. After about two days a corrodable $\mathrm{Mg}$-link releases the hang weight (cf. Ascent and surface spotting). This system not only requires accurate buoyancy calculations, but also some complex and expensive supplementary equipment such as a winch, light sensors and an extra 
acoustic release, which all have to be pressure compensated. The release of glass spheres requires extra ship time and manoeuvring for their recovery, since their loss will induce considerable extra cost.

Another different landing technique used by the BANYULS and GÖTEBORG landers consists of the descent weights being suspended on ropes $0.6 \mathrm{~m}$ under the lander frame. When these weights hit the bottom, the lander is positively buoyant, stops about $0.1 \mathrm{~m}$ from the bottom (filmed during scuba diving), and then stays suspended above the bottom. No feet are required on these landers because the frame never touches the bottom. This technique eliminates the risk of the frame getting stuck in the sediment. USC lander has lead weights that hang just below the frame and prevent the frame from over-penetrating soft sediment. Since landers like the BANYULS and GÖTEBORG are designed never to hit the bottom, bow wave effects on the sediment surface will be less than for more classical designs. The critical factor with this approach is getting the right balance between the negative buoyancy of the ballast weights and the inner chamber tray (damped) to permit a good penetration of the chambers into the sediment. The sensitivity of this lander design to strong bottom currents is yet to be investigated.

Combining a fast descent with a gentle landing can be achieved either by using a parachute drogue or by releasing a ballast weight before reaching the bottom. The only lander to use a parachute drag so far is $R A P$ - 2 . The release of a plasticised nylon drogue is triggered hydrostatically at a pressure around 110 bar and is buoyed up above the instrument on a short tether fitted with a foam float. It decelerates the descent rate from $60 \mathrm{~m} \mathrm{~min}^{-1}$ to $30 \mathrm{~m} \mathrm{~min}^{-1}$.

Theoretically, dropping of a ballast weight prior to landing should be just as simple, using the same type of hydrostatic release as used with the parachute drogue. However, this idea has not yet been used on any lander. The hydrostatic releases have a rather limited precision of about $10 \%$ so triggering depths tend to be imprecise when working in deep water. The release of the weight must not reduce the negative buoyancy so much that it is no longer adequate to push the chamber(s) or electrode(s) into the sediment.

Pressure releases are commercially available for about 500 US\$ (according to 1994 price level).

\section{IMPLANTATION IN SEDIMENT OF CHAMBER AND PROFILING INSTRUMENTS}

A stable landing in an upright position is a crucial factor for a successful lander deployment. For example profiling landers land on the bottom with their electrodes positioned above the sedimentwater interface, and then the electrodes are lowered into the sediment to measure the profiles.

Any lander will to some extent (depending on speed and form) disturb the area where it lands, and for chamber landers it is particularly important to minimise this disturbance. Two different techniques have been developed for chamber implantation (Table 3 ). The first is to fix each chamber under the frame with its lid open so that it is inserted directly into the sediment as the lander arrives on the bottom. This ensures the chamber is inserted into the sediment ahead of the bow-wave. Screens mounted around the chamber limit contamination with suspended sediment before the lid is closed. This technique has been used on MANOP, BECI, ELINOR and BIOSTABLE. The main technical problem is ensuring the descent rate is correct so that the depth of penetration is right, and this is dependent on the softness of the local sediment.

The alternative technique, which has been used on all other chamber landers, is to lower the chambers into the sediment after landing, either individually/mounted on a frame in a damped/ undamped way, or by using a motor to push gently them into the sediment. Corers using damped systems are recognised as causing the least disturbances (BLOMQVIST, 1991; BETT, VANREUSEL, VincX, Soltwedel, Pfannkuche, Lambshead, GoOday, Ferrero and Dinet, 1994). 


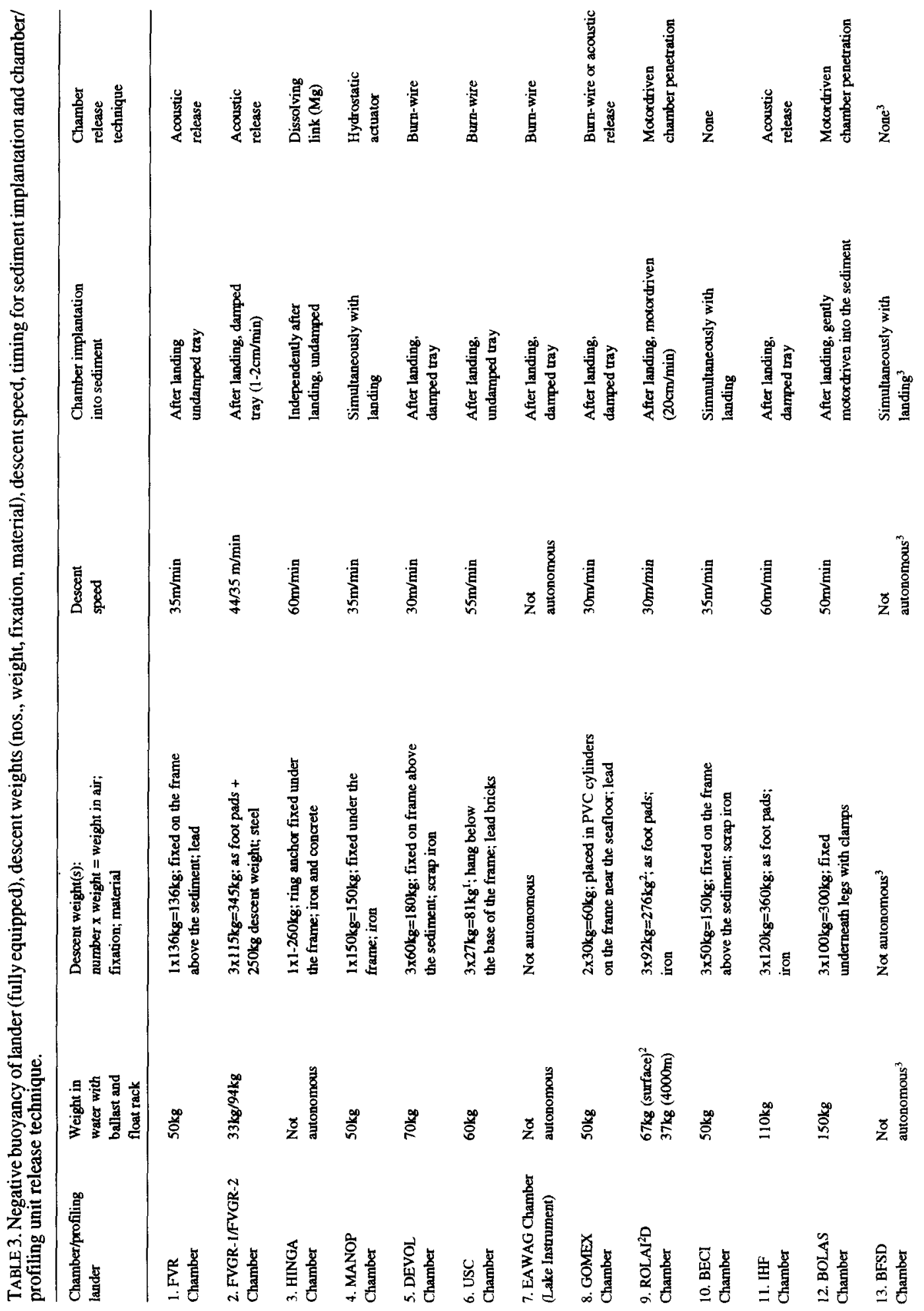




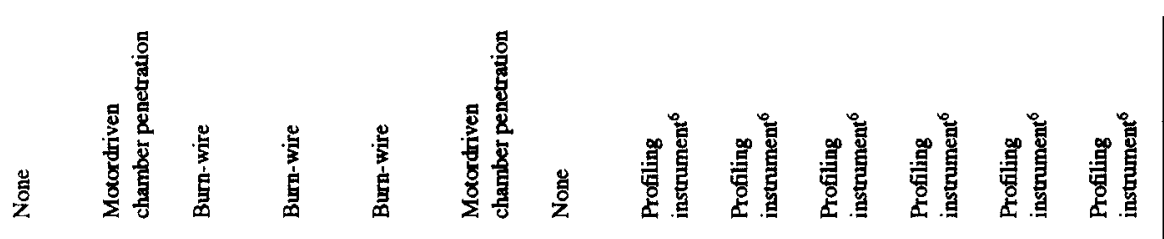

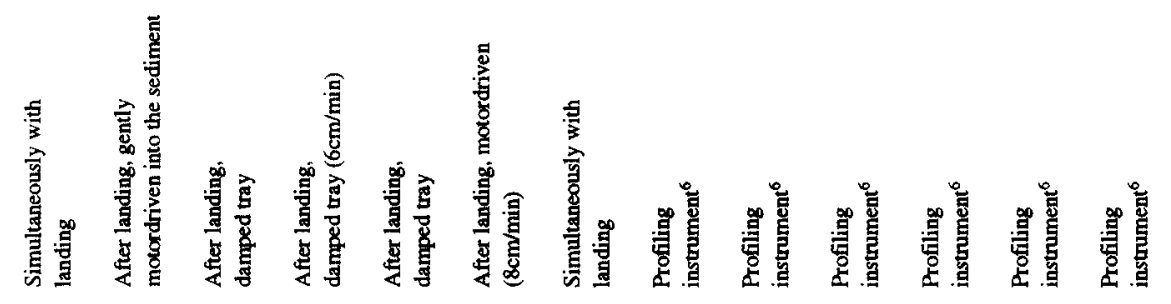

莺

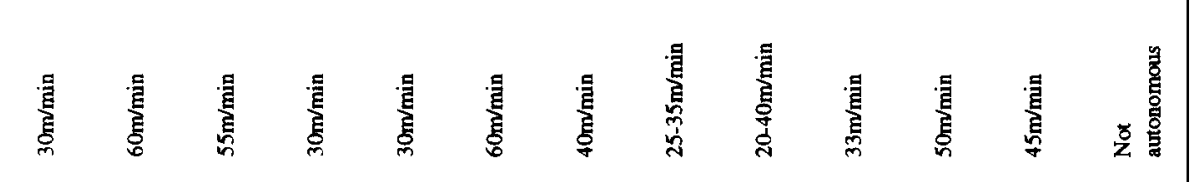

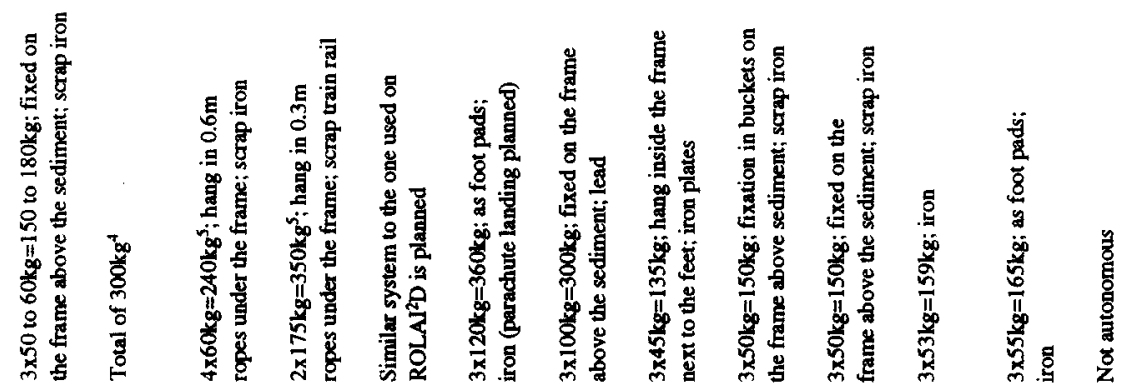

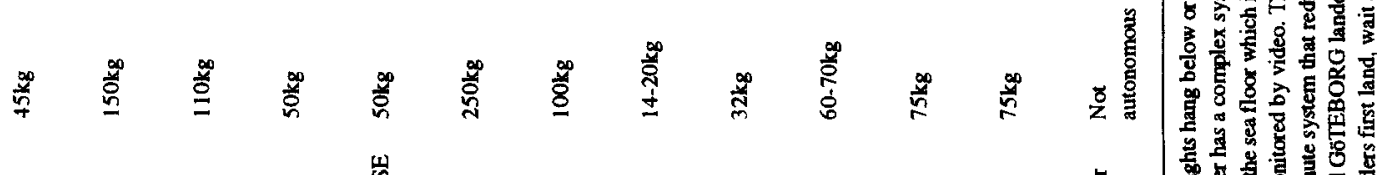

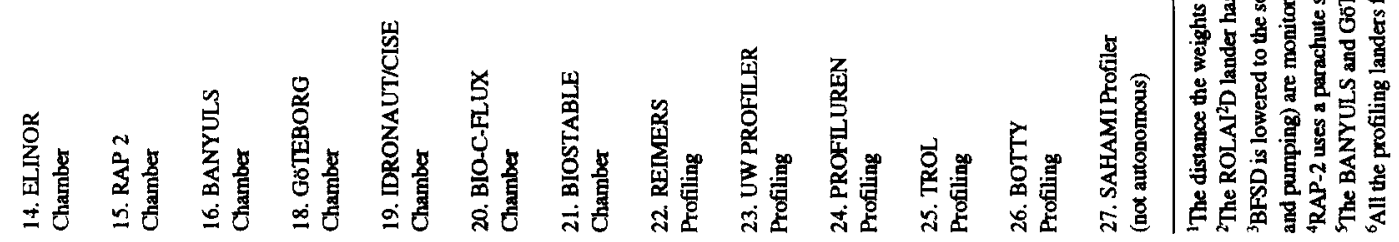


Chamber implantation after landing gives a controlled and reproducible chamber penetration depth and is less reliant on the landing angle being correct, as in those systems using the direct chamber implantation technique. However, if the bottom currents are either weak or nonexistent, sediment resuspended by the landing may contaminate the measurement site.

Implantation can be triggered by means of a timer controlled burn-wire, an acoustic release command from the surface, or by a dissolving magnesium link/bolt. The use of an independent acoustic release is relatively expensive compared to the other techniques and no more accurate time wise than the burn-wire method, although acoustic releases with two release channels are available which enable one channel to trigger the chambers and the other can be used to release the ballast weights. The use of a magnesium dissolving link is "safe", but the dissolving time is so imprecise that release times can vary by several hours.

\section{BOTTOM DEPLOYMENT}

\subsection{Profiling landers}

All the landers that profile across the sediment-water interface with mini- or micro-electrodes are based on the principle developed for the REIMERS profiler. These measurements require that any disturbance to the sediment-water interface and the overlying water is minimised or preferably eliminated. Electrode design is inevitably a compromise between using a minielectrode which is larger and more robust but causes more physical and hydrodynamic disturbances when penetrating the sediment, or a microelectrode which is more fragile but causes less disturbance. While hydrodynamic disturbances are a function of the size of the electrodes they are also influenced by the design of any lander parts that either come in contact with or arrive close to the sediment-water interface. A reduction of the diffusive boundary layer thickness by $25-45 \%$ has been noticed as a result from inserting microelectrodes with diameters of $5 \mu \mathrm{m}$ into sediments (GLUD, GUNDERSEN, REVSBECH and JØRGENSEN, 1994). There are some micro- and mini-electrodes which are commercially available, but most profiling lander constructors prefer to make their own electrodes (e.g. REVSBECH, JØRGENSEN and BLACKBURN, 1980a; REVSBECH, SØRENSEN, BLACKBURN and LOMHOLT, 1980b; REVSBECH, 1989; HELDER and BAKKER, 1985).

All profiling instruments are capable of measuring oxygen profiles and some (REIMERS profiler, UW profiler, PROFILUREN and BOTTY) are also fitted with pHelectrodes. It is essential to know the precise position of the electrode relative to the sediment interface and this is achieved using resistivity probes (ANDREWS and BENNETT, 1981) on the REIMERS profiler, UW profiler, $T R O L$ and BOTTY. Microelectrodes have been developed for measuring $\mathrm{PCO}_{2}$ and have been used successfully for the first time in-situ on the REIMERS profiler (CAI and REIMERS, 1993). Fibre optic $\mathrm{pCO}_{2}$ minisensors have also been successfully used in the deep ocean on the $U W$ profiler (EMERSON, ARCHER and HALES, personal communication). Sulphide microsensors have been used on PROFILUREN (GUNDERSEN, JØRGENSEN, LARSEN and JANNASCH, 1992) and on the REIMERS profiler. Microsensors for temperature have also been mounted on profilers including PROFILUREN and BOTTY. Electrodes for $\mathrm{NO}_{3}{ }^{-}$and $\mathrm{N}_{2} \mathrm{O}$ have been used mainly in freshwater sediments (CHRISTENSEN, NIELSEN, SøRENSEN and REVSBECH, 1990; NIELSEN, CHRISTENSEN, REVSBECH and SøRENSEN, 1990), but have recently been developed for the marine environment.

Profiling landers use a motor to push the electrodes stepwise into the sediment, while they are measuring. The depth resolution depends partly on the size of these steps, but is mainly limited by the outer diameter of the electrode's tip; this varies from 0.025 to $1 \mathrm{~mm}$ for the different profiling instruments (Table 4). 


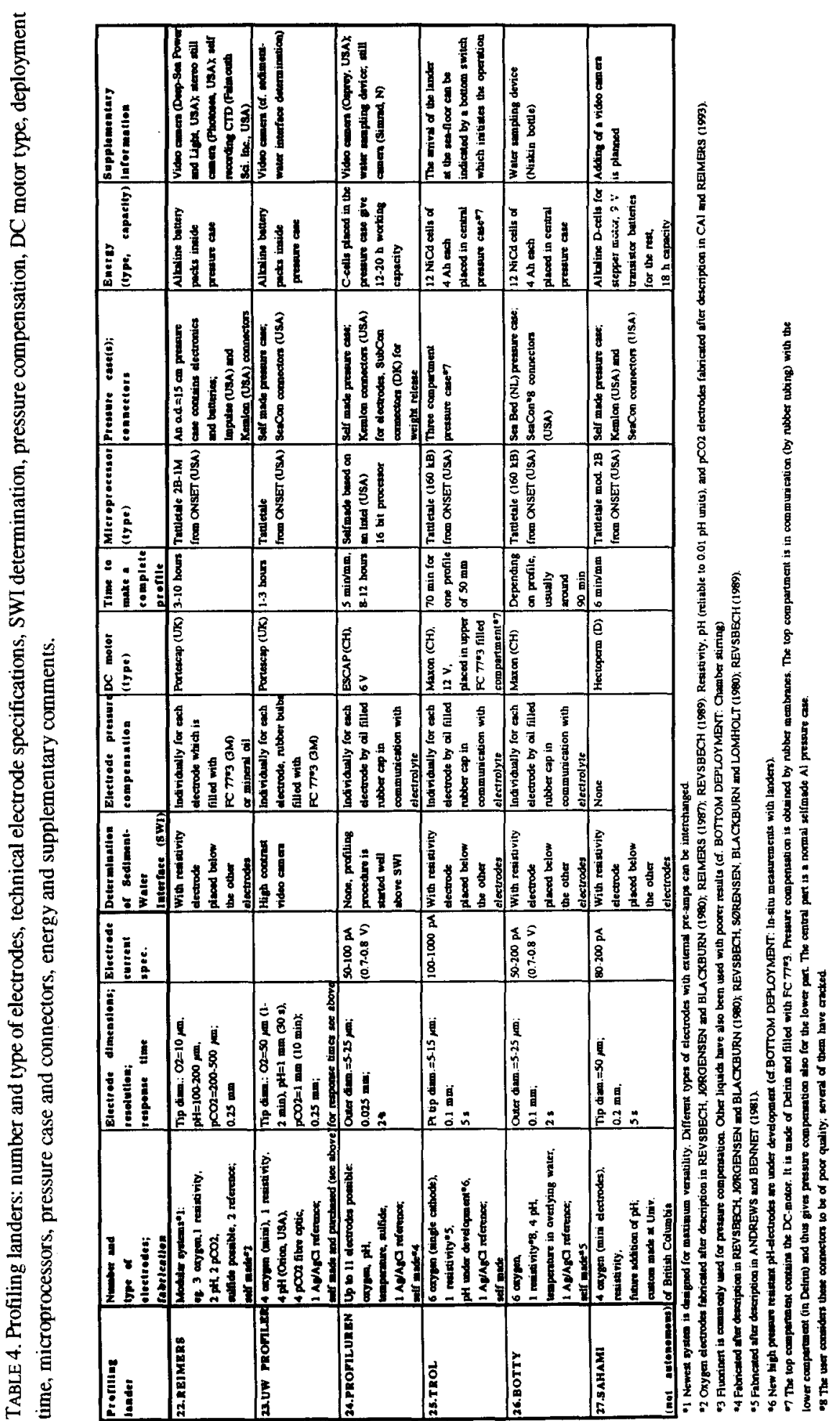




\subsection{Chamber landers: chamber design, surface area and number of chambers}

In situ experiments are carried out within the enclosed environment of the chamber, and fluxes are estimated either by direct measurements of the water chemistry or by sampling it. Many landers also sample and retrieve the sediment incubated up to the surface. The number of chambers on a lander range from $1-4$, and the surface area enclosed by a chamber varies from $177 \mathrm{~cm}^{2}$ for the $B A N Y U L S$ and GÖTEBORG landers, up to $3850 \mathrm{~cm}^{2}$ for the IDRONAUT/CISE chamber. Using a chamber with a larger surface area reduces the variability caused by the fine-scale heterogeneity of bottom sediments so evident in many sea-bed photographs (e.g. RICE, THURSTON and BETT, 1994). This scientific advantage may be offset by greater space requirement and the additional power needed to close sediment recovering scoops. The use of multiple chambers on a lander not only gives a better idea of the variability at each site but also enables controlled manipulative experiments to be carried out, or can be an insurance against the failure of one of the chambers.

Three different chamber shapes have so far been used (Table 5), square (box core type), squared with rounded corners and cylindrical. The shape selected is often determined by the technique used to retrieve the sediment. Another important factor in selecting a particular chamber shape are the hydrodynamics involved in stirring the overlying water. Some modellers claim that the hydrodynamics are easier to model in a cylindrical chamber (BROSTRÖM, 1995), while others prefer a square chamber with rounded corners, because, it is claimed, that the circulation of water in such a chamber more closely resembles in-situ conditions than in other chamber shapes (GLUD, GUNDERSEN, JØRGENSEN, REVSBECH and HÜETTEL, 1995). In the square chamber of $B F S D$, triangular blocks of polycarbonate are used to fill the corners to prevent stagnation.

The water movement inside the chamber is dependent on the stirring mechanism used and the precise location of the stirrer (BUCHHOLTZ-TEN BRINK, GUST and CHAVIS, 1989). The location of any sensors within the chamber will also alter the hydrodynamic conditions and so may influence the measurements. Estimations of hydrodynamics and direct in-situ measurements of boundary layer thicknesses in chambers have been made with microelectrodes (e.g. oxygen) (GLUD, GUNDERSEN, JØRGENSEN, REVSBECH and HUETTEL, 1995), skin friction probes (GUST, 1988), by alabaster dissolution (SANTSCHI, BOWER, NYFFELER, AZEVEDO and BROECKER, 1983; OPDYKE, GUST and LEDWELL, 1987) and by radiotracer uptake by the seabed (SANTSCHI, NYFFELER, O'HARA, BUCHHOLTZ and BROECKER, 1984; HALL, ANDERSON, RUTGERS VAN DER LOEFF, SUNDBY and WESTERLUND, 1989). But before it is possible to recommend an optimal chamber design, further studies and intercalibrations between different chamber designs are needed. However, where a diffusive boundary layer does not limit sediment-water exchange rates, it is probably less critical that the water movements inside chambers resemble those normally taking place in-situ. (see also 6.4. Chamber stirring).

\subsection{Chamber materials and lid closing}

Stainless steel, titanium and aluminium have been used as materials for constructing the chambers (Table 5). Metals have the advantage of being stronger than most plastic materials. There is one report that stainless steel interferes with the oxygen consumption inside the chamber (CRAMER, 1989), but this problem should be relatively easy to overcome with the use of an inert coating, as used for both the chambers made out of titanium (i.e. ELINOR and BIOSTABLE), the aluminium chambers on the HINGA lander and stainless steel chambers on the DEVOL lander. A disadvantage of metals is that if the sediment measured is recovered, the sample can not be visually inspected to estimate roughly the sediment disturbance or see some of the important sediment characteristics such as signs of biological activity (burrows and lebenspurren), any layering of the 
sediment, or the presence of phytodetritus (LAMPITT, 1985). Plastic materials such as Polycarbonate $\left(\right.$ Lexan $\left.^{(\varsigma)}\right)$, PVC and Polymethacrylate (Plexiglass) are often used in the construction of cylindrical chambers (Table 5). Polycarbonate is the least brittle and so is probably the most suitable for a chamber applications. Plastic chambers are lighter and generally less expensive than metal chambers, but they have to have thicker walls because they have lower mechanical strength and are more gas permeable. Thicker chamber walls cause more disturbance when penetrating the sediment, but this can be alleviated by sharpening the edges.

The possibility of using other materials such as glass and composites was investigated prior to the construction of the BANYULS lander, but proved to be unsuitable as alternatives. Composite materials were not considered for the same reasons as explained above (cf. Material choices for lander frames), while contacts with French glass manufacturers (e.g. Saint-Gobain Vitrage, Paris) showed that the mechanical properties of glass, notably shock resistance were poorer than for the other materials.

It is necessary to ensure that there is no chemical exchange between the chamber walls and the water they enclose. Any substances leaching out of the chamber walls may either contaminate the fluxes or interfere with the chemical measurements. Prior to deployment chambers must be thoroughly cleaned (with e.g. diluted acid and distilled water) and then soaked either in ambient sea-water (if possible) or distilled water for a couple of days before use. The chamber must be protected from contamination on deck and, if possible, by the sea-surface film. Such care is of special importance when investigating solutes which occur in very low concentrations, such as trace metals and various dissolved organic compounds. "Blank" chamber deployments, i.e. deployments of chambers on an inert surface (e.g. a sheet of plastics) instead of the sediment surface can be made as controls to provide information on the extent of chemical desorptive/adsorptive interactions between the walls and the water that has been retained. Such exercises are also recommended when it is important to distinguish between processes in the water phase and in the sediment (see 6.6. Water sampling for further discussions of contamination problems).

As the chamber penetrates the sediment, water must be allowed to escape easily. Any excess of pressure will: (a) disturb the sediment, (b) hinder chamber penetration, and (c) generate a hydraulic pressure wave in the pore water down into the sediment. If water is free to flush through the chambers during the descent and during sediment penetration it helps to thoroughly rinse the chamber and ensures that the ambient bottom water contained within the chamber is uncontaminated with water from the higher levels in the water column. The majority of chamber landers are equipped with an upper lid. The two that do not have lids ( $F V R$ and the HINGA chamber) were not designed to recover sediment, and use one-way check/purge valves to let the water escape. Lid designs vary according to the associated equipment (number of electrodes, stirring mechanism and number of water samples taken).

It is essential that the lid seals tightly, and this is achieved variously by the use of weights, springs, magnetic or hydraulic sealing. Verification that the lid has sealed can be made by injecting a tracer that can also provide a measurement of the volume of water in the chamber. Tracers that have been used include $\mathrm{NaBr}$ for $R O L A I^{2} D, B E C I$ and $E L I N O R ; \mathrm{RbBr}$ for $E A W A G ; \mathrm{CsCl}$ for $U S C$ and ${ }^{22} \mathrm{Na}$ for the MANOP lander (SANTSCHI, NYFFELER, O'HARA, BUCHHOLTZ and BROECKER, 1984).

\subsection{Chamber stirring}

Some chemical gradients are established across the sediment-water interface under natural conditions, but once enclosed in a chamber, abnormally steep gradients soon develop. To maintain hydrodynamic conditions as natural as possible, all chamber landers are equipped with stirrers 


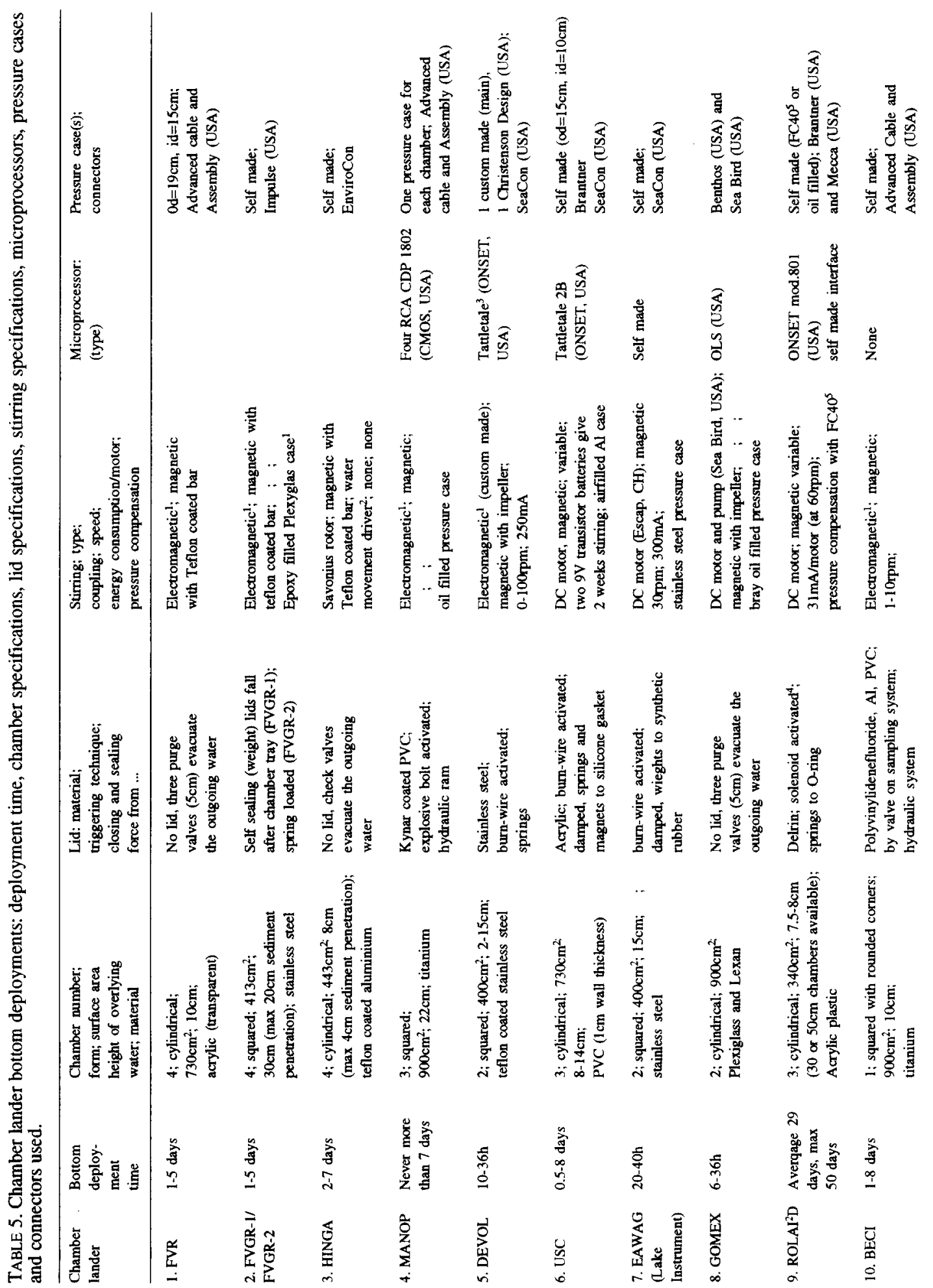




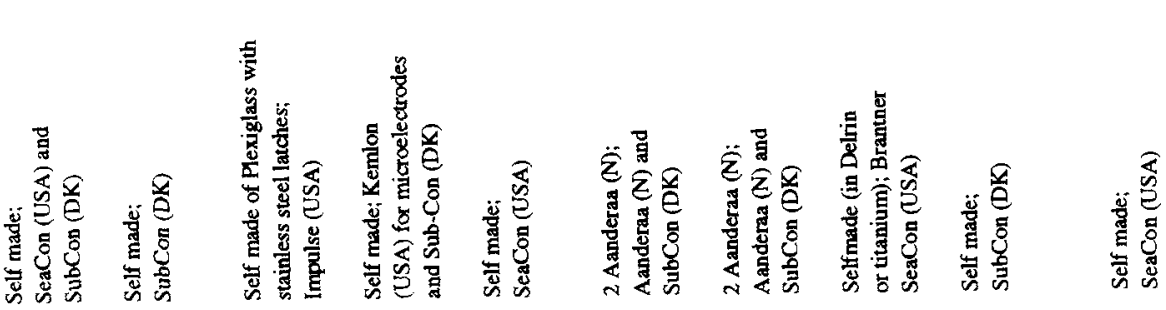

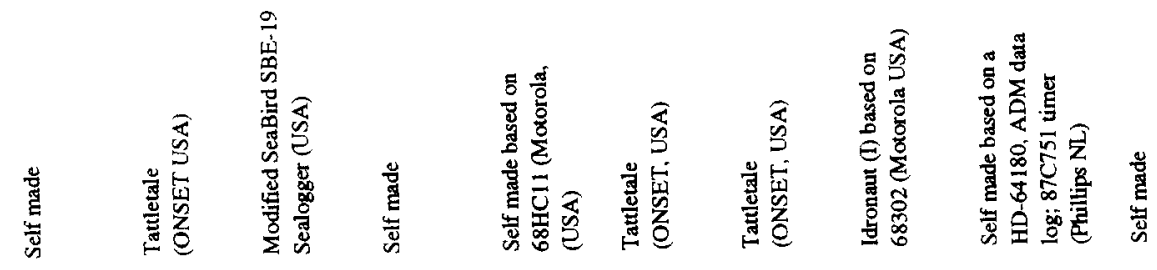

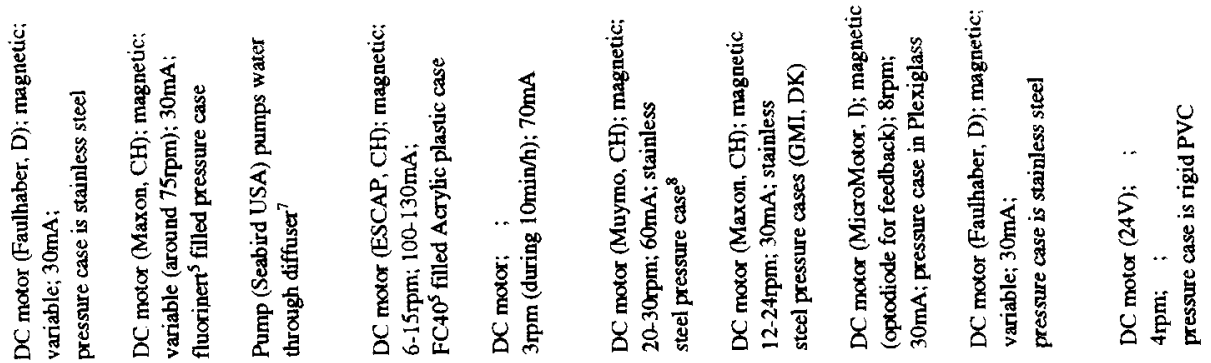

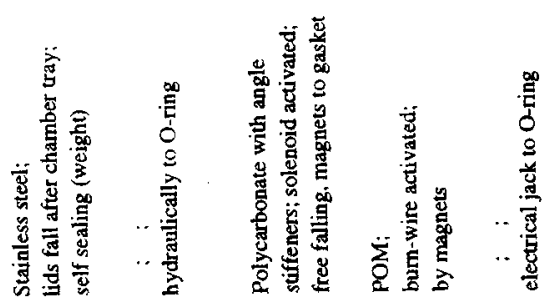

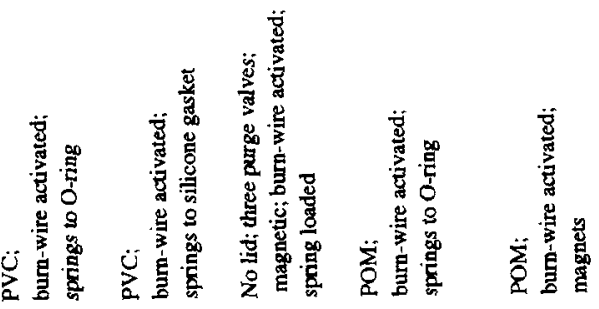

$\begin{array}{cccccccc} & & & \\ 0\end{array}$

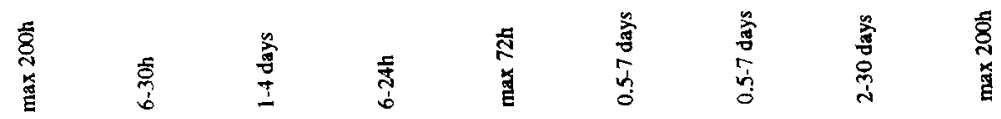

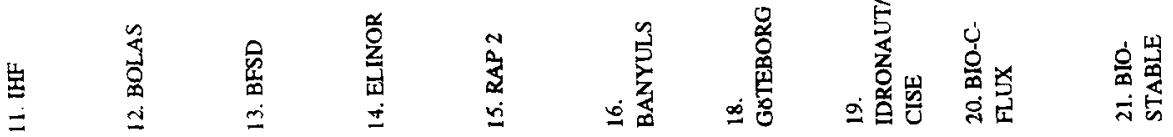

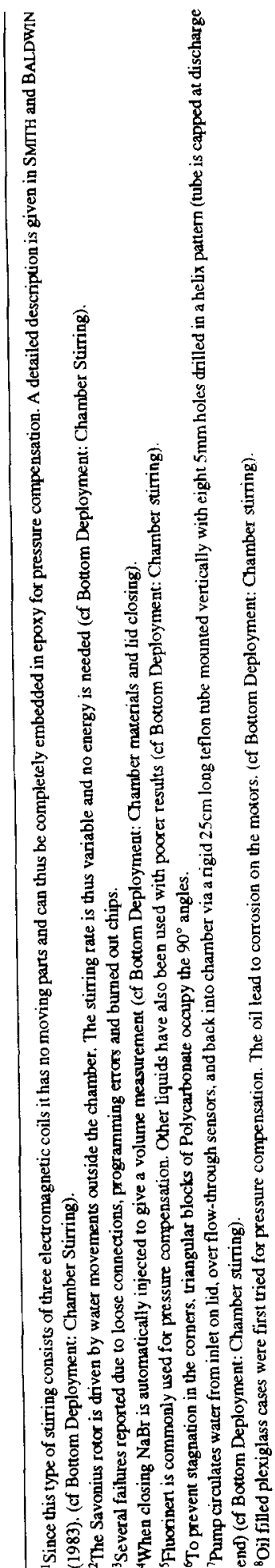


(Table 5). The simplest stirrer, which also has the advantage of consuming no energy, is the Savonius rotor used on the HINGA lander. This stirrer consists of a paddle wheel on top of the chamber which is rotated by the ambient water currents at the deployment site, and runs a Teflon coated stirring bar inside the chamber. However, this solution relies on the bottom currents not being disrupted by the lander frame. In most lander designs a small DC motor is used to rotate a magnet inside a water tight motor housing. The "motor magnet" is magnetically coupled to a magnetic stirrer inside the chamber. A magnetic coupling not only avoids the need for a mechanical coupling but also protects the stirring motor from excessive stress if the stirrer in the chamber is jammed. The motor is housed in either a liquid pressure compensated (often plastic) or an air filled (often stainless steel) pressure housing. Liquid compensation is less demanding in space (depending on motor size), but requires the use of an appropriate liquid for pressure compensation. Fluorinert FC-40 (from 3M company) was used successfully on $R O L A I^{2} D$ and fluorinert FC-77 (from the $3 \mathrm{M}$ company) on MANOP, BECI and ELINOR. Some types of oil, such as pure paraffin, caused corrosion problems on stirring motors on the BANYULS lander, which led to the use of an air filled stainless steel pressure case. Pressure compensation is achieved by connecting a collapsible volume compensator to the motor housing.

Other stirring mechanisms that have been used include electromagnetic stirrers (stepper motors) with magnetic coupling to a stirring bar, and circulation pumps (Table 5). By conducting electric power in a stepwise manner through a number (at least three) of electromagnets placed in a "circle" in the motor house, the stepper motor will rotate a magnetic stirring bar in the chamber. Stepper motors have proved reliable, energy efficient and relatively maintenance free on MANOP, FVGR, $R O L A I^{2} D$ and $B E C I$ and have the advantage of not having moving parts, which can be of importance when either using a liquid pressure compensation system or if embedding the motor in epoxy resin (SMTTH and BALDWIN, 1983). Chamber stirring can also be accomplish by continuously circulating water via a pump (GOMEX, MANOP and BFSD), but requires significantly more energy to perform reliably and so limits deployment duration.

Since stirring is normally maintained during the entire duration of a deployment, it usually has the highest energy demand of all the associated operations. The judicious choice of a stirrer can, therefore, be a crucial factor for the success of long chamber deployments.

Efforts have been put into controlling the stirring of chambers to minimise pressure differences along the sediment surface in the chamber (e.g. GUST, 1990; GLUD, GUNDERSEN, JøRGENSEN, REVSBECH and HUETTEL, 1995). Pressure gradients inside the chamber are believed to affect flux measurements in permeable sediments (e.g. sandy sediments and sediments with many animal burrows) by "importing/exporting" solutes via the sediment between the inside and outside of the chamber (HÜETTEL and GUST, 1992). This minor problem can be overcome by a deeper chamber penetration. Another potential artefact in permeable sediments results from partial pressure gradients, in that convective transport of pore water can take place between the periphery and the centre of a chamber (GLUD, GUNDERSEN, JøRGENSEN, REVSBECH and HÜETTEL, 1995).

\subsection{Microprocessors and lander electronics}

Chamber stirring, water sampling and measurements must all be controlled, monitored and recorded electronically. The choice of controller varies greatly from lander to lander depending on the design requirements. Enormous advances have been made in electronics during the past 20-30 years and so the pioneer landers such as FVR and FVGR-1 used quite primitive electronics.

While designers may still opt to develop their own systems depending on personal knowledge and experience in electronics, a wide range of microprocessors are now commercially available 
which are suitable for lander applications (small, good capacity, easy to program and low energy consumption). The commercial models of different microprocessors presently used in chamber and profiling landers are listed in Table 4 and 5, but new systems are continually becoming available. Most of these include a timer and only demand an interface card to transmit the signals from the microprocessor to the different peripherals (stirring motor(s), burn-wires, solenoids, electrodes etc.).

It is essential to protect the electronics against sea-water and so they have to be housed in pressure-cases (Table 4 and 5), usually of aluminium, stainless steel or titanium. Commercially available spherical glass housings have also been used to protect electronic equipment, and the use of ceramics is a possibility in future (STACHIW, JOHNSON and KURKCHUBASCHE, 1993). These pressure-cases are equipped with pressure resistant bulk-head connectors and cables to link the electronics with the peripherals. Although pressure cases with or without cables and connectors are commercially available, many constructors still prefer to make their own custom-build cases which they then fit with commercial connectors.

There are a number of different connector and cable manufacturers, and the exact types chosen is not very important (as long as the connectors and cables stand up to given specifications) except when the connectors are used for signal transmission from electrodes. In this case, especially when using mini- or microelectrodes, it is essential to choose a cable with a high insulation resistance ( $R$ over $10^{12} \mathrm{Ohm}$ ) under high hydrostatic pressure. If the insulation does not have high enough resistance the signal will be partially or completely lost.

A survey of prices of the different connectors and pressure cases available commercially was made while designing the BANYULS lander and revealed variations of up to a factor of ten for virtually the same material.

\subsection{Water sampling}

During their deployments, all chamber landers collect water samples from the chamber at preprogrammed times. Once these samples have been brought to the surface, they are analysed for various chemical components such as alkalinity, $\Sigma \mathrm{CO}_{2}$, nutrients, DOC, aminoacids, metals, oxygen etc. During extended deployments (i.e. longer than three to five days), or if analysing dissolved gases (e.g. oxygen) the water samples need to be poisoned (e.g. mercury solution on $R A P-2$ ) to stop bacterial development. If dissolved gases are to be analysed, the samples must be drawn into glass samplers rather than into sampler container made of gas permeable plastics.

The simplest, and most widely used method of drawing water samples is by using spring- or weight-loaded syringes. The syringes are held cocked and triggered by a range of mechanisms including:- (a) a timer controlled corrosive link (burn-wire used by mostlanders), (b) solenoids (e.g. FVR, $R O L A I^{2} D, E L I N O R$ and BIOSTABLE), (c) a timer- or microprocessor-controlled DC motor $(B E C D)$, (d) by stepper motor of the same type as used on a Rosette water sampler (e.g. BOLAS). The burn-wire technique is simple and well tested. It requires an electrical power connection to each syringe and another (common to all syringes on marine landers) to a cathode, which "earths" the current from the burn-wire to the water. The cathode must be electrically isolated from any metal part of the lander. Plastic coated wire such as some fishing lines can be used as burn-wire. For deployments in fresh water, each burn-wire needs to be placed in a short Plexiglass tubing filled with saturated solution of $\mathrm{NaCl}$, and sealed with rubber stoppers. A solenoid system requires two wires (positive and negative). The solenoid triggering system is probably easier and faster to arm, but demands more development and testing. It also needs to be pressure protected (liquid bath or pressure case) before use which takes up more space. BECI employs two four-conductor wires to 
operate DC motors that can sample an indefinite number of syringes (current design employs 20). After sampling it is important to prevent sample leakage during the rest of the deployment or during recovery either by locking the syringes in the untriggered position, or by using pressure plates to stop off the sampling lines (USC) or the use of one-way valves. Syringes used for water sampling are easily modified to inject tracers into the chamber after contact with the sea-bed.

Stepper motor triggering systems seem to be reliable for operating syringes, but all syringes used must be grouped around the pressure protected stepper motor.

Other water sampling systems that have been used include spring loaded bellows for collecting large volume samples and vinyl bulbs on the $U S C$ landers. A sampling pump system was tried on MANOP, but proved to be unreliable and so was replaced by spring loaded syringes. BOLAS uses a "bottle" sampler within the chamber, which works with the same principle as a "Niskin bottle" and collects a large $(250 \mathrm{ml})$ water sample at the end of the deployment. The IDRONAUT/CISE chamber contains a two channel peristaltic pump, one channel to collect the sample and the other to supply replacement water. On $B F S D$ which is used only to depths of $50 \mathrm{~m}$, an air-filled container is filled by hydrostatic pressure with sample when a solenoid controlled valve opens a fill-line between the chamber and the container.

Contamination of the samples must be avoided at all costs. If the sampling system consists of plastic syringes connected by tubing to the chamber lid, then careful rinsing with distiled water should be adequate. For more complex systems, more extensive cleaning will be necessary to avoid contamination, which needs to be followed up with blank measurements and checks, especially for the study of trace constituents. A thorough study of the potential contamination of water enclosed by a chamber and the associated sampling system was carried out by BERELSON and HAMMOND (1986). It was shown that Nylaflow ${ }^{\oplus}$ and Tygon $^{\odot}$ contaminate the water with silica and alter hydrogen ions concentrations $(\mathrm{pH})$, whereas Nylaflow $^{\odot}$ also promoted a precipitation of calcium carbonate from the supersaturated water. It was also found that aluminium surface may absorb silica. Plexiglass, nylon and latex, however, showed no significant contamination effects. In general, any plastics used should be transparent since colouration is by pigments which often contain additives that can result in contamination. Problems (and suggested solutions) with using metals as chamber materials have been treated above (cf. 6.3. Chamber materials and lid closing).

There has to be compensation for the volume of water removed during sampling. In most cases this occurs through diffusion barrier, an open tube between the chamber and the ambient bottom water which is long enough to avoid diffusive exchange with the outside. Water enters through the tube as the sample is drawn and knowing the volume of sample and the external concentrations of solutes it is simple to model the quantitative effect of the replacement water. Some chamber landers collect external reference water samples either with Niskin bottles or with syringes (Table 6).

To calculate the benthic solute fluxes from rate of change of solute concentrations within chambers, the volume of water (or height of water column) enclosed by the chamber has to be known precisely. This information can be obtained in a variety of ways. If a chamber lander retrieves the incubated sediment intact, the water column height can be measured directly back on-board ship. Some landers are equipped with a simple device that only can move one way and that is pushed upwards by the sediment as the chamber tray penetrates it (used on GÖTEBORG lander as a backup system). The height to which it is displaced then corresponds to the water column height in the chamber. Another method is to inject a precise amount of tracer into the chamber and its dilution is used to estimate of the volume of water in the chamber (see discussion on tracers above in section 6.3. Chamber materials and lid closing). A camera mounted on the lander can be used to record not only the height of the water column in the chamber (if using transparent chambers), but also the degree of disturbance of the sediment caused both during landing and normally by macrofaunal 
activities. It is still uncertain as to which method of determining chamber volume is the most reliable, and this deserves further study.

\subsection{Pore water and sediment sampling}

$R O L A I^{2} D$ has two separate systems for in-situ pore water sampling, one suitable for "deeper" pore water sampling (SAYLES, 1979) and a "whole core squeezer" (BENDER, MARTIN, HESS, SAYLES, BALL and LAMBERT, 1987) for high resolution, vertical sampling of pore water near the sediment-water interface. A module for high resolution $(1 \mathrm{~mm})$ pore water sampling using an equilibration probe (gel "peeper"; KROM, DAVISON, ZHANG and DAVISON, 1994) is being developed for the BANYULS- and GÖTEBORG-landers, which will replace one of the four chambers during deployments.

Chamber fluxes and pore water profiles of oxygen have been measured at the same site by mounting the $U W$ profiling instrument onto the DEVOL flux chamber tripod (ARCHER and DEVOL, 1992).

After deployment, most chamber landers retrieve the incubated sediment. This not only enables visual inspection of the sediment, but also makes it feasible to continue biological or geochemical experiments and analyses back onboard ship.

Different principles have been used to close off the bottom of the chambers on retrieval. One is based on the "classical" sediment sampling techniques (box core type) where the closure is by scoop(s) forced through the sediment either by springs (as on FVGR-2, IHF and DEVOL landers) or by hydraulic cylinders pressurised at the surface (as on BECI, ELINOR and BIOSTABLE), or by a motor (as on $B O L A S$ ) which collects separate sediment samples outside the chamber.

Another method (as used in the "multiple corer" type) relies on the sediment being held inside the chambers by the suction created by the sealed upper lids, and protective scoops which close once the chambers have pulled out of the sediment (BARNETT, WATSON and CONNELY, 1984). This technique, used on the BANYULS- and GÖTEBORG-landers, has the advantage that it demands less force and results in very little sediment disturbance (BLOMQVIST, 1991; BETT, VANREUSEL, VINCX, SOLTWEDEL, PFANNKUCHE, LAMBSHEAD, GOODAY, FERRERO and DINET, 1994).

A third method is the so-called sphincter closing mechanism (BURKE, 1968), in which the closure is made by rotating an "orange peel mechanism" (used on $R O L A I^{2} D$ ). This technique has seldom been used for sampling sediments, but is reported to be reliable and to result in little sediment disturbance (Table 6).

\subsection{In-situ measurements with chamber landers}

Most chamber landers carry out one or more in-situ measurements. Most of these measurements are made with standard electrodes (e.g. oxygen) modified to operate in the extreme conditions (pressure, temperature, salinity, fouling, etc.) on the sea-bottom. There is now a wide range of systems commercially available which are suitable for use on chamber landers. These electrodes were developed essentially to be used for water column profiling and sampling (e.g. CTD instruments). Parameters normally measured on landers are conductivity (salinity), temperature and pressure (depth), and it should be relatively easy to add the measurement of bottom currents, fluorescence and turbidity, since appropriate sensors are available for use on CTD's. Sulphide and $\mathrm{pCO}_{2}$ microsensors have recently been used on profiling instruments (cf. 6. 1. Bottom deployment: Profiling landers), and manganese sensors have been successfully used on deep-towed instruments detecting hydrothermal vents. 


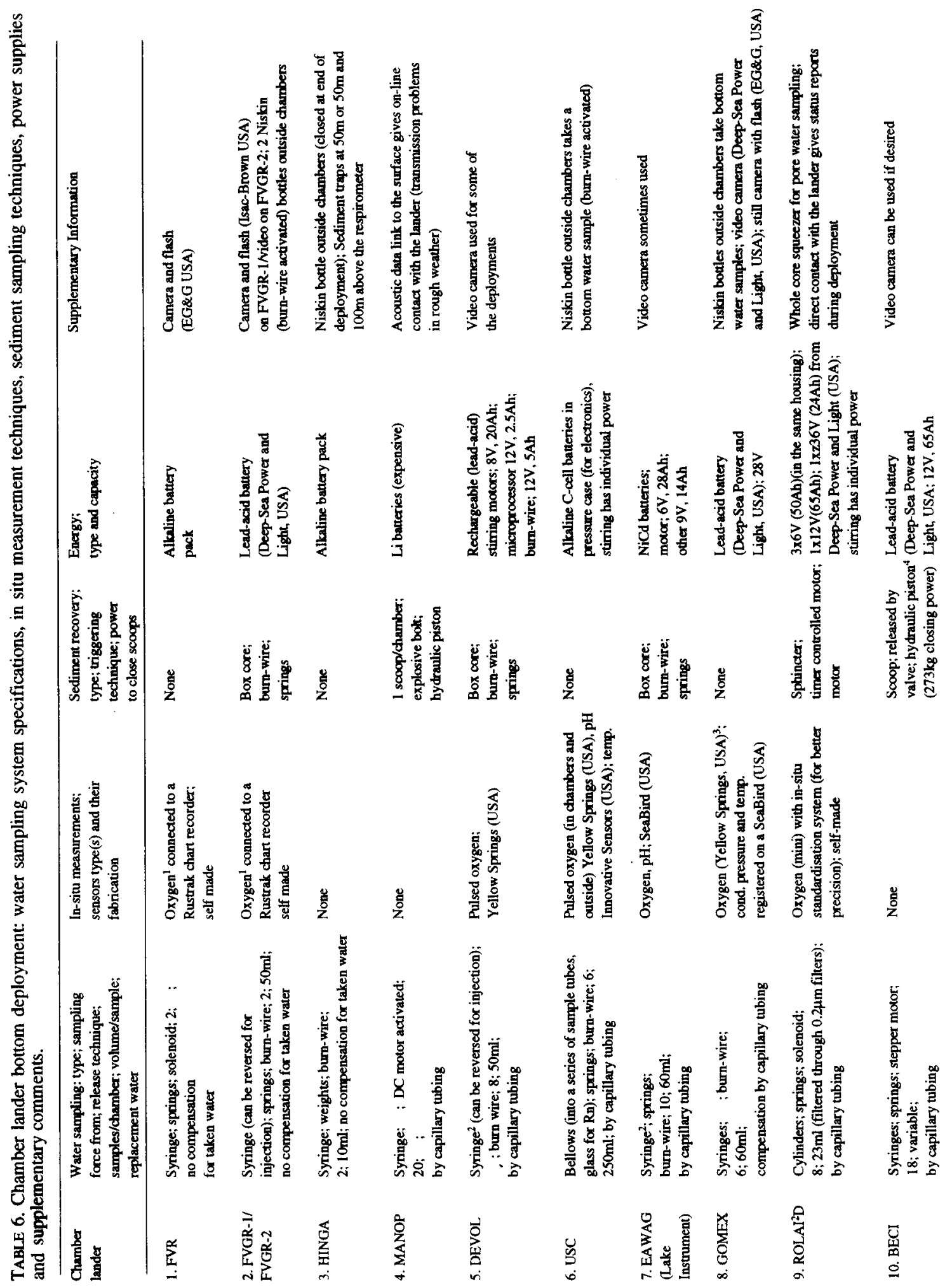



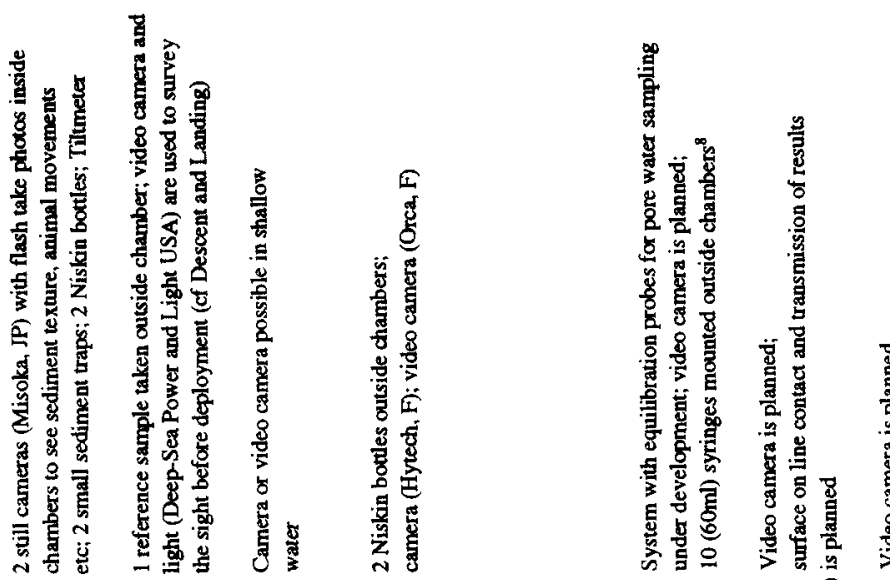

亭

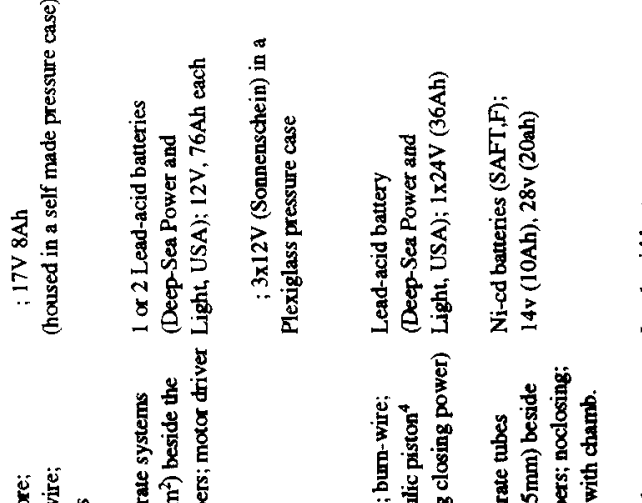

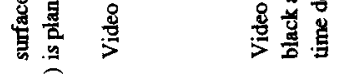

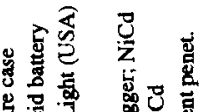

siln

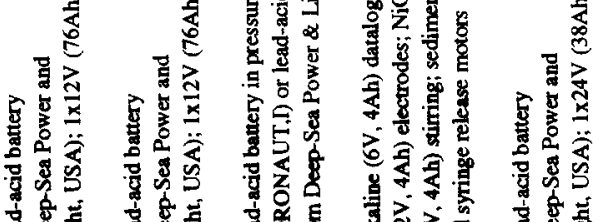

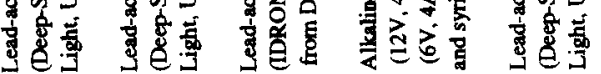

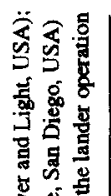

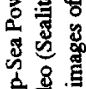

造

弯

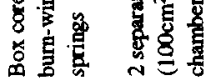

II

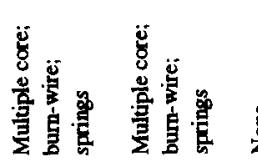

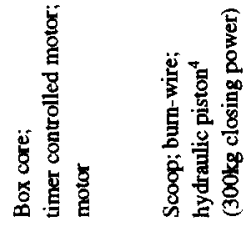

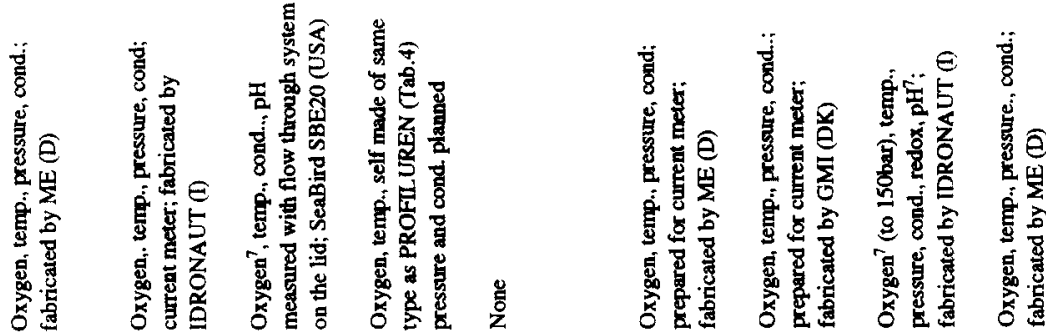

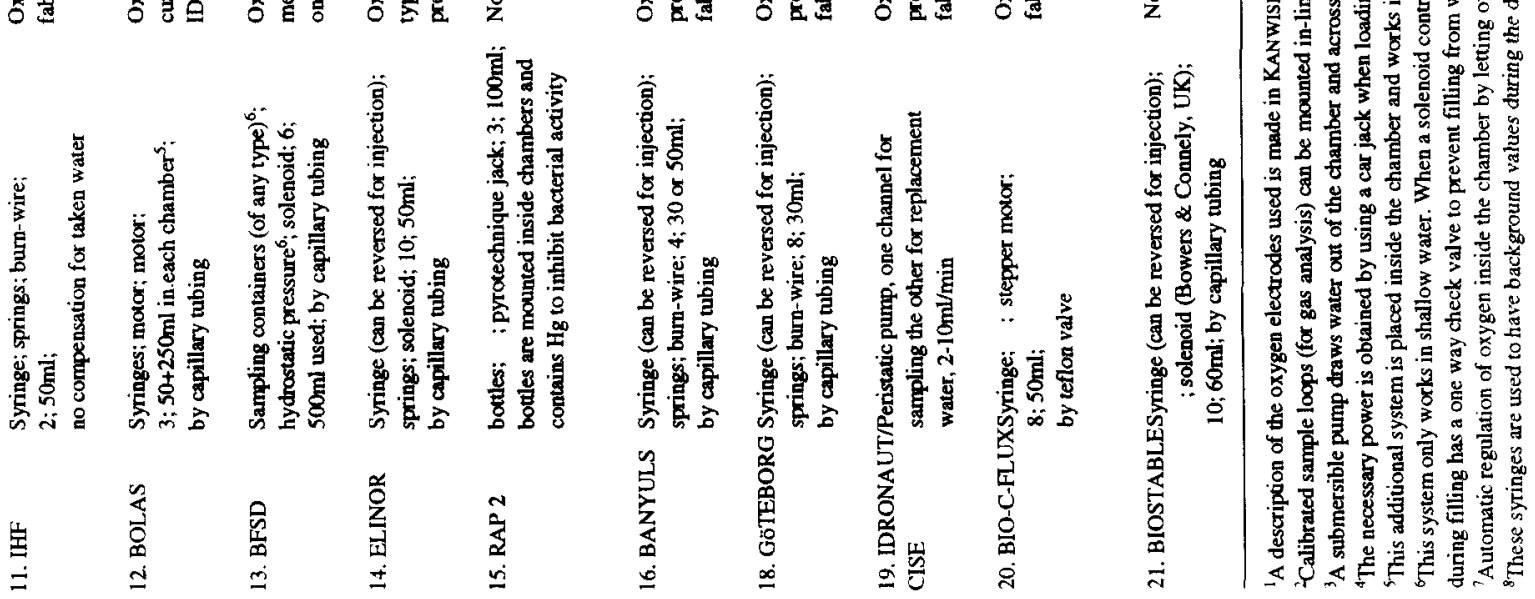


During long-term chamber deployments and/or in organic-rich sediments with high oxygen consumption rates, the measurements of benthic solute fluxes may be affected by diminishing oxygen concentrations in the chamber. To avoid such artefacts, a system to maintain the oxygen concentration, as well as the $\mathrm{pH}$, at the ambient level during chamber incubations was developed by HALL (1984) and RUTGERS VAN DER LOEFF, ANDERSON, HALL, IVERFELDT, JOSEFSON, SUNDBY and WESTERLUND (1984). A coil of Teflon tubing was used to let oxygen diffuse into the water within the chamber and injections of $2.5 \mathrm{M} \mathrm{NaOH}$ maintained the $\mathrm{pH}$. The oxygen system had to be limited to deployments on continental margins (less than $2000 \mathrm{~m}$ depth), because regular oxygen cylinders were used. Two chamber instruments have automatised this system for oxygen (the IDRONAUT/CISE and the BFSD; the latter mainly intended for polluted sediments) and one for $\mathrm{pH}(I D R O N A U T / C I S E)$.

An alternative way of estimating $\mathrm{\Sigma CO}_{2}$ (instead of measuring it on discrete water samples at the surface using e.g. coulometry) is to measure $\mathrm{pH}$ ( in-situ) and alkalinity (of collected water samples). The use of $\mathrm{pH}$ electrodes have been successful during short term deployments on profiling landers (e.g. REIMERS Profiler, UW Profiler, PROFILUREN, BOTTY; see also section 6.1), but for deployments longer than several hours at pressure equivalent to depths $>200 \mathrm{~m}$, there are problems particularly with the fast decomposition of the liquid/gel in the reference electrode of pH electrodes. Recently the first successful deployments lasting 24-48 $\mathrm{h}$ at depths of $3800-4800 \mathrm{~m}$ of a lander carrying $\mathrm{pH}$ electrodes has been reported by BERELSON, HAMMOND, MCMANUS and KILGORE (1994). Solid state pH sensors (VANDEN VLEHBERT and DE ROOIJ, 1988) are being tested for such long-term deployments under high pressure, at NIOZ in the Netherlands.

Most chamber and profiling landers use electrodes that were developed and tested by the constructors or by their colleagues. The work of assembling, calibrating and maintaining a reliable suite of probes is demanding in time and expertise. Commercially available electrodes and dataloggers have now been adapted for use on several landers and should ameliorate some of these technical and resource demands (c.f. Table 4 and Table 6 for details and makes).

Minielectrodes for oxygen have been used on chamber landers (e.g. $R O L A I^{2} D$ and $E L I N O R$ ), which have faster response times and consume less oxygen than the macroelectrodes. Since minielectrodes take up less space in the chamber than macroelectrodes, they may offer advantages which compensate for their greater fragility. However during chamber experiments concentration changes are slow, so a fast response time is notessential. In large chambers the oxygen consumption of the bigger electrodes is relatively insignificant, but can be calculated from the current running in the probe. $R O L A I^{2} D$, which has been used for relatively long deployments, has an in-situ standardisation system to improve the precision of its oxygen electrodes.

Electrodes and the electronic instruments for the in-situ measurements usually constitute an important part of a lander budget and are of crucial importance for successful deployment. It is not cost-effective in ship-time or research-time if the results are either lost or rendered unreliable by faulty instruments. Mistakes and bad instrument selection can often be avoided by consulting with experienced users of the electronics.

\subsection{Other equipment}

Some landers have video or still cameras mounted to survey the landing and the bottom deployment. BOLAS has a camera inside the chamber to take photographs of animal movements on the sediment surface. There are now several commercially-available pressure-protected camera systems suitable for lander use. Their use tends to be of greatest interest, during the initial stages of a deployment when the behaviour of the lander in water and on its arrival at the sea-floor is poorly known. 
Some chamber landers are equipped with communication systems that relay back to the ship the successful operation of all stages of the lander's performance, its landing, chamber penetration, lid closure and lift-off. The simplest system is to release floats at particular phases of the operation to signal their successful completion (e.g. $D E V O L)$ but over deep water the floats may not be spotted. Two landers, MANOP and $R O L A I^{2} D$, used direct communication with the surface during deployment. An acoustic link can not only monitor the successful functioning of the lander, but also can be used to reprogram it from the surface. However, this link demands ship-time, may be difficult to operate in bad weather and transfer capacity through acoustic signals is limited.

Acoustic communication systems are expensive and may be superfluous if the lander is to be deployed only for a few days. They could be of importance for status checks during long-term deployments. More important is that success of recovery at the surface is greatly improved if the device is fitted with an acoustic beacon because the ship can be navigated to find the device using the Doppler shift of the signal. Even in rough seas or thick mist the vessel can be manoeuvred to within tens of meters of the beacon.

\subsection{Electrical energy}

For many of its functions, a lander requires energy (for stirring, solenoids, bum-wires, electrodes, stepper motors, cameras etc.). The longer the deployment, the greater the energy storage capacity is needed, which for chamber landers mostly used for stirring, so designs and components need to minimise energy consumption.

The energy can be supplied by different types of batteries. Lithium type batteries are not rechargeable, but combine high capacity with small size. The nickel-cadmium batteries are generally rechargeable and can give high currents, but they have a tendency to discharge at zero current and so they are unsuitable for long-term deployments. The batteries most widely used on landers are oil pressure compensated lead-acid (car type) batteries. While these are heavy and take up a lot of space, they have a high capacity (70-80 Ah for 12 V) and rechargeable, so in the long run they are relatively inexpensive.

When calculating requirements for energy capacity, a very important aspect to take into consideration is that at cold temperatures most batteries loose up to half of their nominal capacity. Detailed information on the behaviour of each specific type of battery is normally available from the manufacturer.

Some constructors recommend splitting up the power supplies into several independent units and keeping high current (e.g. for camera flash) and stable voltage supplies (e.g. for timers) separated. Security systems (acoustic releases, pingers, VHF surface radios, ARGOS satellite locateable transmitters, surface flashes, etc.), and computer memories for data storage and programming normally have their own individual energy supplies (Table 4 and 6).

\section{ASCENT AND RECOVERY}

There are several examples of landers that have been lost either because they were stuck in the sediment, trawled away by fishermen or lost for other unknown reasons.

All autonomous profiling and chamber landers use flotation (foam or glass spheres) to lift off the sea-bed and return to the surface after release of descent weights (cf. Descent and landing). Glass spheres have been used on most landers because of their relatively low cost. Although guarantied to full ocean depth, an early version of $I H F$ is thought to have been lost as a result of implosion of glass spheres. The shock-wave from the implosion of one sphere can trigger others 
and so destroy whole rigs. All spheres should be pressure tested prior to use and any glass spheres that show signs of internal flaking should be discarded. Note also that the operators of French and American manned submersibles refuse to operate anywhere near instruments equipped with glass float spheres because of the risk of implosion. Syntactic foam is more expensive than glass spheres, but cannot implode, moreover it can be made into a custom designed shape. The downside with syntactic foam is that although it generally takes up less total volume than a glass float package, the weight in air for foams depth-rated to $6000 \mathrm{~m}$ can be more than double that of glass buoyancy. However, for working at shallower depths $(<2000 \mathrm{~m})$, the foams do not suffer from this disadvantage.

Alternative buoyancy under development are titanium spheres and low density thixotrophic liquids (Balmoral, UK).

There are principal methods of attaching buoyancy. It can be attached directly to the top of the frame (used by all but two landers), or by a cable or a rope. The former method makes for a bigger and heavier instrument. The latter solution, used on $U S C$, may make the lander more susceptible to strong bottom currents, but makes it easier to grapple and handle during recovery, especially in bad sea conditions. The HINGA lander has been used at the base of a mooring with a string of other instruments and the float package mounted above it.

The need for excess of float capacity after ballast release is an important consideration. If too little buoyancy is used the lander may fail to pull out of the bottom, so that it is either lost or has to be recovered by dredging; as occurred during the first trials with TROL and BOLAS. These two landers originally had about $25 \mathrm{~kg}$ excess buoyancy which proved to be insufficient, so extra float spheres had to be added. The float capacity needed is a compromise between providing enough buoyancy to pull a lander out of a sticky sediment, and keeping the requirement for ballast weight as low as possible. If a chamber lander is designed to retrieve sediment it is not only subjected to a greater sediment suction on pull-out, but is also heavier on its return. For the landers reviewed herein, the buoyancy required after ballast release varies from 45-250 $\mathrm{kg}$ (Table 7).

The ballast weights are usually held in place by either a lever or toggle mechanism. The mechanism is released either by an electro-mechanical drive (most commercial acoustic releases), a corrosion of a burn-wire, dissolution of a link (e.g. $\mathrm{Mg}$ ) or breakage of a link by an explosive charge (K.L. SMITH time releases; IOS CR200 (PHILLIPS, 1980)). Serial or parallel redundant backup with more than one release can be provided using various ways of suspending the weights. Most landers have two independent systems for ballast release. Acoustically-controlled releases are handy but expensive, their advantage is that using a system controlled from the surface, the time of recovery can be chosen to provide the most appropriate conditions (weather and time). Most acoustic releases produce precision time "pings" which can be used to estimate the distance to the lander and the direction the ship needs to be tuned to lessen the distance. The acoustic source will indicate the ascent has started and gives the ascent rate so that it can be estimated where and when it will reach the surface. Reception of acoustic sources can be problematic where there is strong temperature stratification or the bottom topography is exceedingly rugged, but most modern systems have horizontal ranges of up to $15 \mathrm{~km}$ and operate to depths of at least $6 \mathrm{~km}$. However, difficulties have been encountered in positioning $B O T T Y$ and other instruments at depths $>3000 \mathrm{~m}$, and acoustic release systems are not $100 \%$ reliable. Other release systems used on landers are microprocessor controlled burn-wires and dissolving magnesium links. The burn-wire solution is a less expensive alternative to the acoustic release, but once programmed, the weight release time can not be changed. A dissolving magnesium links are reliable but imprecise in timing, and should not be used for deployments longer than about three days.

Once it has surfaced, it is important to spot and recover the lander as fast as possible, not only 
because the samples need to be processed and the rig prepared for a new deployment, but also to ensure the lander does not drift out of the search zone demanding extra ship time. It is surprisingly difficult to sight an object at the surface at a range of a kilometre in even quite calm wave and swell conditions. The more detection aids that are fitted the better; these can include flashing lights, an antenna fitted with a flag, a radar reflector, an acoustic beacon, a VHF direction finder and an "ARGOS" satellite transmitter. Once again all these systems should have independent power sources capable of running the device for at least 12 hours.

Short distance spotting can be made with a VHF radio transmitter on the lander and a directional receiver on the ship.

For long distance positioning (world covering), an ARGOS (CLS, Toulouse, France and NACLS, Landover, MD, USA) satellite transmitter can be used (Table 7). A satellite positioning system has the advantage of giving the position whenever, and wherever, the equipment reaches the surface. A lander that is trawled away or was stuck in the sediment and comes up a month later than expected will be spotted by the satellite positioning system, and can be recovered. All the above described surface spotting systems are available commercially.

The greatest risk of damage to the lander (and human handlers) occur during launching and recovery. It is very important to prevent the lander from swinging and bouncing while hanging from a crane or A-frame. A successful launch and recovery avoiding damage to the lander is more a question of the skill of the ship crew and the sea state than of lander design. Some landers have been lost or damaged during recovery because of lack of communication between people working on deck and on the bridge, e.g. by having propellers running when they should not. One way to facilitate the recovery is to have separate floats, one ca. $2 \mathrm{~m}$ from the instrument and the other(s) at the end of a line, attached to the instrument, and if this line is at least $30 \mathrm{~m}$ long, it is normally easier to grapple than the lander itself. The floats will spread out down-wind of the lander. The shipcan then approach the gear up-wind and parallel to the line, so that it can be easily grappled from a safe distance. Once the line is hooked and secured on a winch, the instrument can be pulled closer and taken on-board with propellers stopped and the ship drifting with the wind away from the lander. Another recovery method is to attach a line to the gear from a rubber boat (used on $R$ N Polarstern), but this technique is more restricted to good weather conditions. None of these landers floats with much above the water surface. Attaching a lifting wire from a ship is made easier if the frame is fitted with a big lifting ring.

When lifting the instrument onboard it is important to take account of the considerable dynamic stress on the lifting line that can result from the movement of the vessel in the swell. Lines and ropes used in the marine environment are worn out with time and through usage (e.g. by chafing, and sun bleaching). Some brands of rope (e.g Kevlar and Spectra) are exceedingly strong when new but can loose their mechanical properties, often without showing any clear signs of their weakened condition, through mechanical mis-use, for example by being bending under strain through sharp angles. If accidents and losses are to be avoided then we recommend that wire $>14 \mathrm{~mm}$ diameter are used in preference to ropes for landers weighing up to $2000 \mathrm{~kg}$.

\section{PERSPECTIVES AND REMAINING TASKS}

During the "European benthic lander research and technology workshop" (Bremen, Nov. 1993) the utility of landers versus other techniques such as the benthic laboratories being planned in USA, Japan and Europe (see e.g. THIEL, KIRSTEIN, LUTH, LUTH, LUTHER, MEYER-REIL, PFANNKUCHE and WEYDERT, 1994) were discussed. The conclusions reached were as follows:-

In-situ studies on the sea-floor involve advanced deep-sea technology which is still in an early 


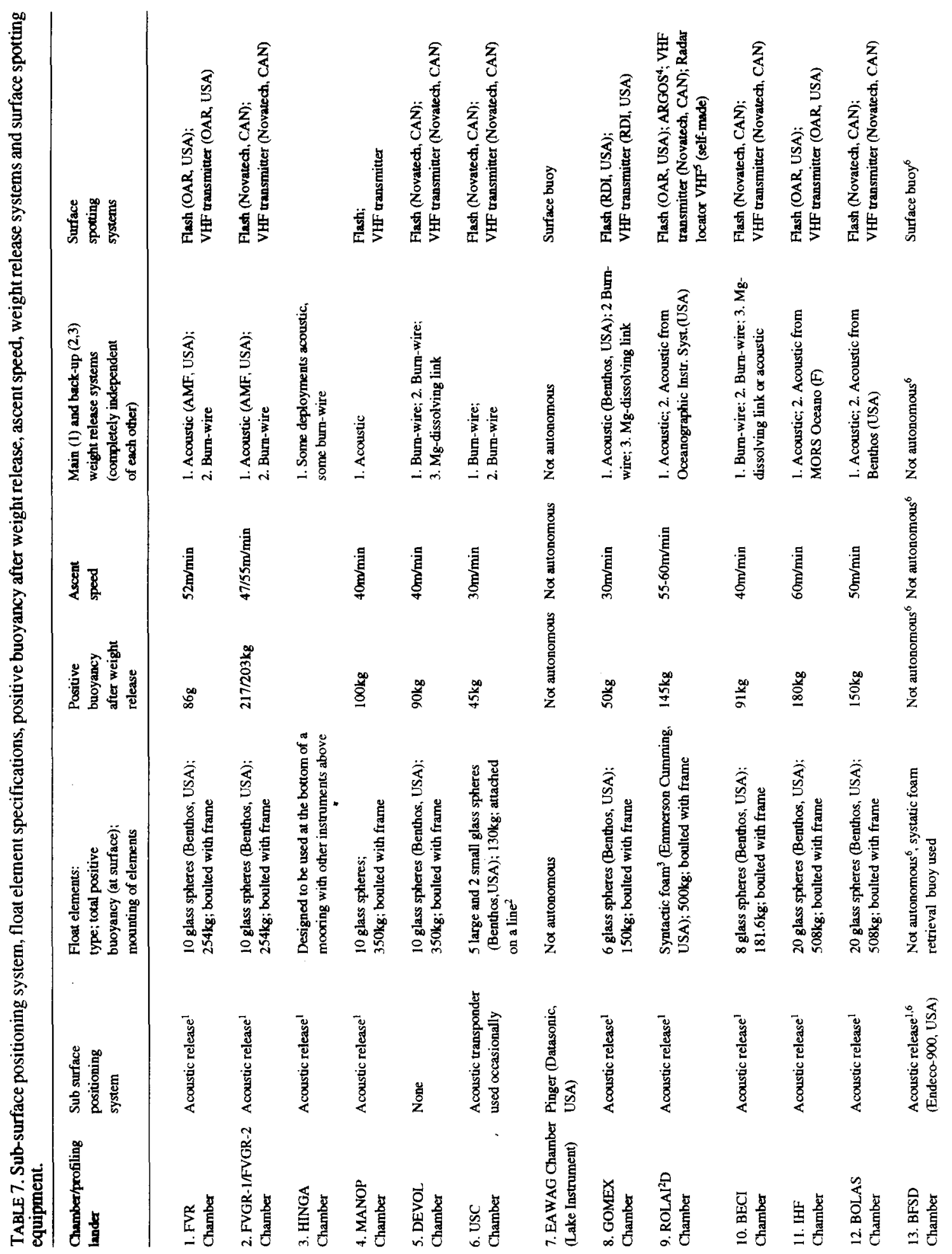




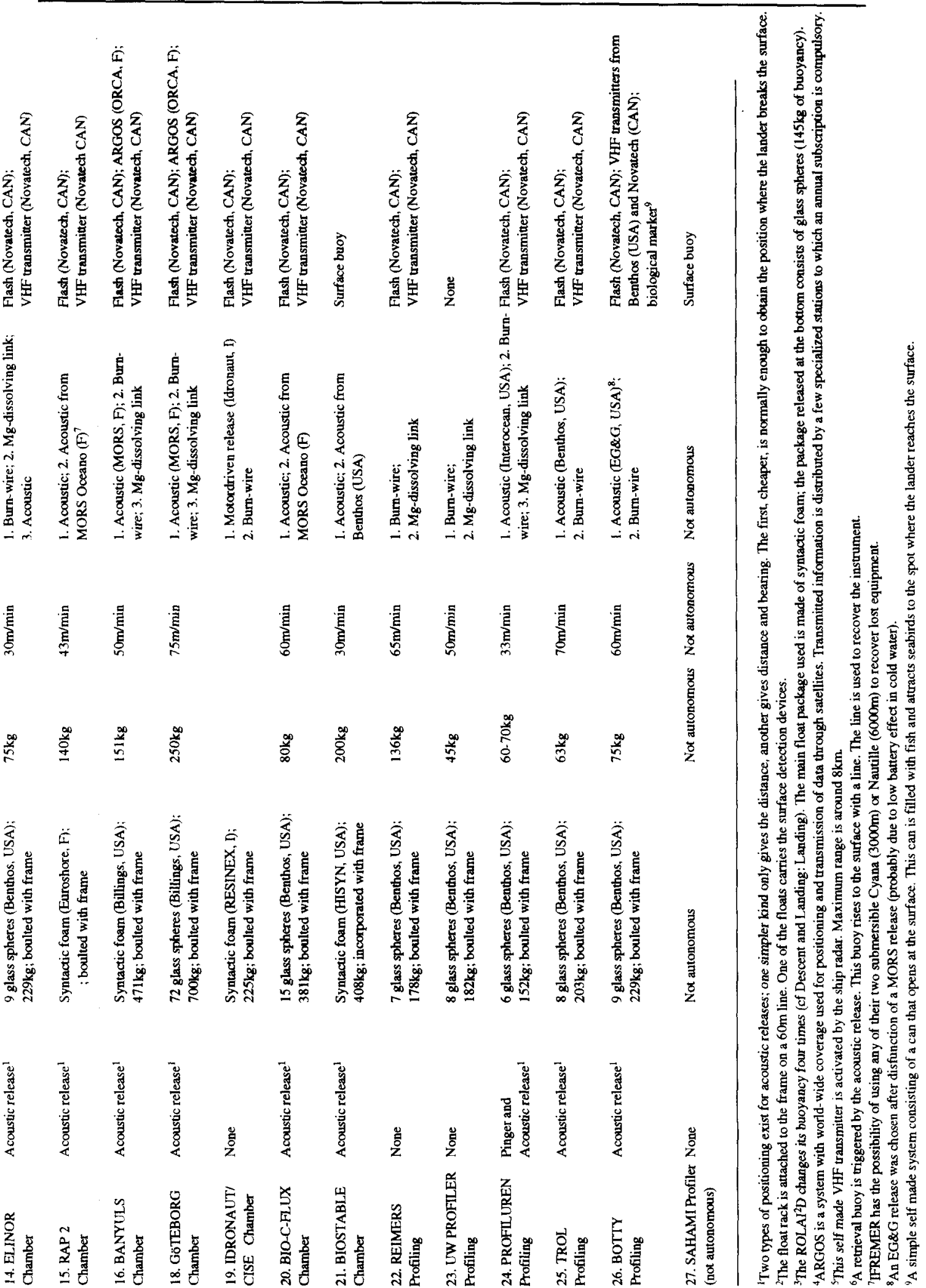


stage of development and is often at the cutting-edge of technological advance. Most research groups developing and deploying benthic landers have the capacity to operate only one or a few instruments, even so the results obtained from successful deployments of landers continue to provide an important and unique insights into the deep-sea environment and benthic processes. It is, therefore, of major concern that the future initiatives on benthic in-situ technology should be based on a realistic and progressive development of the current and novel technical developments. The research strategy adopted should derive from defined questions and goals of marine research, rather than being determined by the technological challenge.

The waiting time of a research vessel on station during a deployment is now a major component of the research costs and can be minimised by effective design both in terms of science that can be achieved and the cost effectiveness of ship-operations. So cruises should be coordinated whereby multiple deployments of landers can be pre-programmed. An alternative option is the construction of landers with the ability to operate continuously or intermittently for long periods of time, optimally for a month up to a year which do not require frequent servicing from a surface vessel. Such long-term deployments are presently done routinely with hydrographic instruments. Benthic instruments have, however, the disadvantage of gradually changing the benthic environment they are observing and thus modifying the properties of processes being monitored. A "bottom crawler", lander able to move in between deployments, thereby continually exploring unaffected sea-floor, has recently been constructed. This type of instrument requires more stable sensors, long-term maintenance and calibration procedures. Repeated deployments of sensors and flux chambers require a yet unresolved method to remove or avoid biological growth on sensor surfaces and chamber walls. Also, the high capacity energy sources and lander vehicles capable of movement require further technical development.

Among the motivations for future marine science is the need to reach a global understanding of the processes controlling the chemistry of and element cycling in the ocean. A large database of high quality in-situ benthic biogeochemical fluxes is required for this purpose. Such data are obtained today by the use of benthic lander systems, but their capacity is still very limited (Table 8) and can not provide extensive time-series of key parameters. Novel ideas including advanced technological developments are, therefore, needed to cope with the important questions in oceanography. Some main demands are:

- Long term deployment capability (6-12 months) with frequent observations which requires sufficient power supply and data storage capacity;

- $\quad$ Monitoring of long term variations (decades) in areas of key interest for global change aspects;

- Long term monitoring of sites influenced by human activities, e.g. deep-sea waste dumping or mining;

- Interactive process studies involving a benthic station which can recognise defined events, e.g. a sedimentation pulse, and then activate measurements and sampling;

Time-series of samples at varying frequencies with in-situ preservation;

Data transmission to sea surface and via satellite to shore-based institutes;

Equipment for active site selection, manipulation and experimentation, e.g. by video or by imaging fibre optic cables.

It is strongly recommended that these research objectives are approached by a stepwise construction of the benthic instrumentation required along several lines of development: 
TABLE 8. Benthic lander deployment areas.

\begin{tabular}{|c|c|}
\hline $\begin{array}{l}\text { Chamber/profiling } \\
\text { lander }\end{array}$ & Deployment areas \\
\hline 1. FVR & N.W. Atlantic \\
\hline \multicolumn{2}{|l|}{ Chamber } \\
\hline 2. FVGR-1/FVGR-2 & N. Pacific (e.g. San Diego Trough. Patton Escarpment); \\
\hline Chamber & N.W. Atlantic; Central N. Pacific \\
\hline 3. HINGA & N. Atlantic (from the Equator to $38^{\circ} \mathrm{N}$ ) \\
\hline \multicolumn{2}{|l|}{ Chamber } \\
\hline 4. MANOP & E. Pacific; N. Pacific \\
\hline \multicolumn{2}{|l|}{ Chamber } \\
\hline 5. DEVOL & Skan Bay (Alaska); Tres Marias depression and Mexican shelf and slope off \\
\hline Chamber & Mazatlan; Santa Catalina Basin; Washington continental shelf and slope \\
\hline 6. EAWAG Chamber & Lakes of Luzern, Sempach, Zug, Baldegg and Alpnach in \\
\hline (Lake instrument) & Switzerland \\
\hline 7. USC & Central and southern California Margin (shelf, slope and rise); \\
\hline Chamber & Central and Eastern Equatorial Pacific \\
\hline 8. GOMEX & Gulf of Mexico; E. Greenland shelf; Conception Bay (E. Canada); MidAtiantic \\
\hline Chamber & Bight off E. USA. \\
\hline 9. ROLAI $^{2} \mathrm{D}$ & Bermuda (Atlantic time series) \\
\hline \multicolumn{2}{|l|}{ Chamber } \\
\hline 10. BECI & St. Monica basin; California borderland; Peru Margin; Cape Hatteras region \\
\hline Chamber & (N.W. Atlantic); W. Equatorial Pacific; N.E. Atlantic; W. Equatorial Atlantic \\
\hline 11. IHF & N. of the Azores; E. Biscaye; around Madeira (all in the N. Atlantic) \\
\hline \multicolumn{2}{|l|}{ Chamber } \\
\hline 12. BOLAS & N. Atlantic; Adriatic Sea and other Mediterranean sites; \\
\hline Chamber & Indian Ocean (off Kenya, Somalia, Oman) \\
\hline 13. BFSD & Shelter Island Basin (San Diego); San Diego Bay; Sinclair Inlet (Washington State) \\
\hline \multicolumn{2}{|l|}{ Chamber } \\
\hline 14. ELINOR & Skagerrak. Kattegat (N.E. North Sea); S. Atlantic (off Namibia); S. Atlantic (off \\
\hline Chamber & Brazil); upwelling areas off Chile; Limfjorden (DK); German Bight \\
\hline 14. RAP 2 & N.E. Atlantic; Equatorial Atlantic \\
\hline \multicolumn{2}{|l|}{ Chamber } \\
\hline 16. BANYULS & N.E. Mediterranean \\
\hline \multicolumn{2}{|l|}{ Chamber } \\
\hline 18. G6TEBORG & Skagerrak (N.E. North Sea); Gullmar Fjord (W. Sweden) \\
\hline \multicolumn{2}{|l|}{ Chamber } \\
\hline 19. IDRONAUT/CISE & Lagoon of Venice (I); Orra Lake (I); La Spezia Harbour (Ligurian Sea) \\
\hline \multicolumn{2}{|l|}{ Chamber } \\
\hline 20. BIO-C-FLUX & S. Baltic Sea \\
\hline \multicolumn{2}{|l|}{ Chamber } \\
\hline 21. BIOSTABLE & Arabian Sea \\
\hline \multicolumn{2}{|l|}{ Chamber } \\
\hline 22. REIMERS & Santa Catalina Basin; San Clemente Basin; Patton Escarpment; Central California \\
\hline Profiling & Slope and rise; Santa Barbara Basin; Ceara Rise; Central N. Pacific; N.W. African slope \\
\hline 23. UW PROFILER & Mexican continental shelf; Washington shelf and slope; Equatorial Atlantic; \\
\hline Profiling & N.W. Atlantic; W. Equatorial Atlantic; W. Equatorial Pacific; Ceara Rise \\
\hline 24. PROFILUREN & Skagerrak, Kattegat (N.E. North Sea); S. Atlantic; Bermuda; W. Pacific; \\
\hline Profiling & Bight of Aarhus (DK); Bight of California \\
\hline 25. TROL & N.E. Atlantic; Adriatic Sea and other Mediterranean sites; \\
\hline Profiling & Indian Ocean (off Kenya, Somalia, Oman); OMEX program sites \\
\hline 26. BOTTY & Southern Ocean in the polar front area; Amundsen Sea; Bellinghausen Sea \\
\hline \multicolumn{2}{|r|}{ 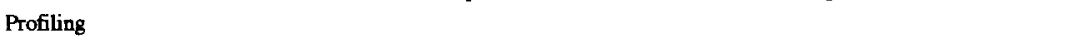 } \\
\hline $\begin{array}{l}\text { 27. SAHAMI Profiler } \\
\text { Profiling }\end{array}$ & $\begin{array}{l}\text { Coastal fjords and inlets of British Columbia (often in } \\
\text { polluted sediments around paper mills) }\end{array}$ \\
\hline
\end{tabular}


1) Non-targeted deployments and measurements on short time scales (hours to days) should be performed by landers of relatively simple design and low cost.

2) For long term observations (months) an abyssal station may be gradually built up which combines more functions, sensors and experimental capacities and which allows interactive operation via data transmission to the surface. A modular construction is important in which experimental units may be designed by individual scientists and applied in the system. The system must have internationally uniform components for power supply, connectors, data storage and data transmission. The risk that the placement and presence of the instrument will affect the monitored parameters and processes must be seriously considered.

3) The problem of measurements and experimentation on selected sites should be approached by the use of submersibles or benthic laboratories (i.e. on-line ROV-type systems) which can place and operate equipment and conduct experiments with the aid of manipulators. ROV's are also useful for mapping physical and chemical parameters on the sea-floor on scales of $1-10^{-3} \mathrm{~m}$. On a larger scale of tens of $\mathrm{km}$, an instrument may be required with the ability to move close to but above the sea-floor using remote sensing techniques which can land to carry out measurements and take benthic samples.

\section{ACKNOWLEDGEMENTS}

We thank K.L. Smith for valuable information on his landers, and I. Priede, M. Rutgers van der Loeff and K.L. Smith for belpful comments on an early version of the manuscript. Financial support for this review was given by the Swedish Natural Science Research Council (NFR), CNRS/INSU and Université Pierre et Marie Curie (Paris VI) in France.

\section{REFERENCES}

ALLER, R.C., P.O.J. HALL and P.D. RUDE (1987) Solute distributions and flux estimates in bioturbated sediments of the Panama Basin. EOS, 68, 1749.

ANDREWS, D. and A. BENNETT (1981) Measurements of diffusivity near the sediment- water interface with a finescale resistivity probe. Geochimica et Cosmochimica Acta, 45, 2169-2175.

ARCHER, D. and A. DEVOL (1992) Benthic oxygen fluxes on the Washington shelf and slope: A comparison of insitu microelectrode and chamber flux measurements. Limnology and Oceanography, 37, 614-629.

ARCHER, D., S. EMERSON and C.E. REIMERS (1989b) Dissolution of calcite in deep-sea sediments: pH and O2 microelectrode results. Geochimica et Cosmochimica Acta, 53, 2831-2845.

ARCHER, D., S. EMERSON and C.R. SMITH (1989a) Direct measurements of the diffusive sublayer at the deep sea floor using microelectrodes. Nature, 340, 623-626.

ARMSTRONG, J.D., P.M. BAGLEY and I.G. PRIEDE (1992) Tracking deep sea fish using ingestible transmitters and an autonomous sea-floor instrument package. In: Wildlife Telemetry, I.G. PRIEDE and S.M. SWIFT, editors, Ellis Horwood, Chichester, pp 376-386.

BALZER, W. (1978) Untersuchungen über Abbau organicher Materie und Nährstoff-Freisetzung am Boden der Kieler Bucht beim Übergang vomoxischen zum anoxischen Milieu. Ph. D. dissertation, University of Kiel, Germany, pp 129.

BARBANTI, A., R. BONIFORTI, G. CICERI, W. MARTINOTTI and T. VIRTANEN (1992) BIMS-Benthic Instrumentation and Monitoring System for investigating the properties of the water-sediment interface. In: Proceedings of "Oceanology International 1992, The Global Ocean" Conference, Brighton.

BARNETT, P.R.O., J. WATSON and D. CONNELY (1984) A multiple corer for taking virtually undisturbed samples from shelf, bathyal and abyssal sediments. Oceanologica Acta, 7, 399-408.

BENDER, M., W. MARTIN, J. HESS, F. SAYLES, L. BALL and C. LAMBERT (1987) A whole core squeezer for interfacial pore water sampling. Limnology and Oceanography, 32, 1214-1225. 
Berelson, W.M., D.E. Hammond, J. MCMANus and T.E. KIgGORE (1994) Dissolution kinetics of calcium carbonate in equatorial Pacific sediments. Global Biogeochemical Cycles, 2, 219-235.

BERELSON, W.M. and D.E. HAMMOND (1986) The calibration of a new free-vehicle benthic flux chamber for use in the deep sea. Deep-Sea Research, 33, 1439-1454.

BEREl.son, W.M., D.E. HAMMOND, K.L. SMITH JR., R.A. JAHNKE, A.H. DEVol, K.R. HiNGA, G.T. Rowe and F. SAYLES (1987) In-situ benthic flux measurement devices: bottom lander technology. Marine Technology Society, 21, 26-32.

Bett, B.J., A. VanReusel, M. VincX, T. Soltwedel, O. PfannKuChe, P.J.D. Lambshead, A.J. Gooday, T. FERRERO and A. DINET (1994) Sampler bias in the quantitative study of deep-sea meiobenthos. Marine Ecology Progress Series, 104, 197-203.

BILLETT, D.S.M., R.S.LAMPITT, A.L. RICE and R.C.F. MANTOURA (1983) Seasonal sedimentation of phytoplankton to the deep-sea benthos. Nature, 302, 520-522.

BIRD, A.R. and L.F. MOCKROs (1986) Measured fluid forces on an accelerated/decelerated circular cylinder. 18th Annual Offshore Technology Conference, Houston, Texas, pp 157-163.

BLOMQVIST, S. (1991) Quantitative sampling of soft-bottom sediments: problems and solutions. Marine Ecology Progress Series, 72, 295-304.

De Bovee, F., A. Tengberg, P.O.J. Hall, Y. Barbouty, H. Le Beller, B. Brilloit and L. LANDEN (1995) A new free-vehicle benthic chamber lander. (In preparation).

BRoström, G. (1995) The effect of rotation in benthic flux chamber experiments. Deep-Sea Research, (Submitted).

BuchHOLTZ-TEN BRINK, M.R., G. GuST and C. CHAvis (1989) Calibration of a stirred benthic growth chamber. Deep-Sea Research, 36, 1083-1101.

BURKE, J.C. (1968) A sediment coring device of $21 \mathrm{~cm}$ diameter with a sphincter core retainer. Limnology and Oceanography, 13, 714-718.

CALLENDER, E. and D.E. HAMMOND (1982) Nutrient exchange across the sediment-water interface in the Potomac river estuary. Estuarine Coastal and Shelf Science, 15, 395-413.

CAI, W.-J. and C.E. REIMERS (1993) The development of $\mathrm{pH}$ and $\mathrm{pCO} 2$ microelectrodes for studying the carbonate chemistry of pore waters near the sediment-water interface. Limnology and Oceanography, 38, 1776-1778.

CHADWICK, D.B., S.D. STANLEY and S.H. LIEBERMAN (1993) A benthic flux chamber for monitoring pollution exchange rates at the sediment-water interface. MTS' 93 Technology Requirements in the Nineties, Marine Technology Society Conference Proceedings, Long Beach, California, 11 pp.

ChRISTENSEN, P.B., L.P. NIELSEN, J. SøRENSEN and N.P. REVSBECH (1990) Denitrification in nitrate rich streams: Diurnal and seasonal variation related to benthic oxygen metabolism. Limnology and Oceanography, 35, 640-651.

CICERI, G., S. MARAN, W. MARTINOTTI and G. QUEIRAZZA (1992) Geochemical cycling of heavy metals in a marine coastal area: benthic flux determination from pore water profiles and in situ measurements using benthic chambers. Hydrobiologia, 235/236, 501-517.

CRAMER, A. (1989) A common artefact in estimates of benthic community respiration caused by the use of stainless steel. Netherlands Journal of Sea Research, 23, 1-6.

DEVOL, A.H. (1987) Verification of flux measurements made with in situ benthic chambers. Deep-Sea Research, 34, 1007-1026.

DEVOL, A.H. and J.P.CHRISTENSEN (1993) Benthic fluxes and nitrogen cycling in the sediments of the continental margin of the eastern North Pacific. Journal of Marine Research, 51, 345-372.

DICKINSON, W. and F.L. SAYLES (1992) A benthic chamber with electric stirrer mixing. Technical Report WHOI92-09, Woods Hole Oceanographic Institution, USA, $17 \mathrm{pp}$.

EPPING, E. and W. HELDER (1995) In-situ oxygen microprofiles and their modelling. Results from the northern Adriatic Sea. Marine Ecology Progress Series, (Submitted).

GLUD, R.N., J.K. GUNDERSEN, N.P. REVSBECH, and B.B. JøRGENSEN (1994) Effects on the benthic diffusive boundary layer imposed by microelectrodes. Limnology and Oceanography, 39, 462-467.

GLud, R.N., J.K. GUNDERSEN, N.P. REvSBECH, B.B. JøRGENSEN and M. HÜETTEL (1995) Calibration and pes formance of the stirred flux chamber from the benthic lander ELINOR. Deep-Sea Research, (in press).

GLUd, R.N. J.K. GuNDERSEN, B.B. JøRGENSEN, N.P. REVSBECH and H.D. SCHULZ (1994) Diffusive and total oxy sen uptake of deep-sea sediments in the eastern South Atlantic Ocean: in situ and laboratory mea surements. Deep-Sea Research, 41, 1767-1788.

GUNDERSEN, I.K. and B.B. JøRGENSEN (1990) Microstructure of diffusive boundary layers and the oxygen uptake of the sea floor. Nature London, 345, 604-607. 
GUNDERSEN, J.K. and B.B. JøRGENSEN (1991) Fine-scale in situ measurements of oxygen distribution in marine sediments. Kieler Meeresforschungen, 8, 367-380.

GUNDERSEN, J.K., B.B. JøRGENSEN, E. LARSEN and H.W. JANNASCH (1992) Mats of giant sulphur bacteria on deepsea sediments due to fluctuating hydrothermal flow. Nature, London, 360, 454-455.

GusT, G. (1988) Skin friction probes for field applications. Journal of Geophysical Research, 93, 121-132.

GusT, G. (1990) United States Patent, Patent number, 4,973,165. Nov. 27.

HALES, B., S. EMERSON and D. ARCHER (1994) Respiration and dissolution in the sediments of the western North Atlantic: estimates from models of in situ microelectrode measurements of porewater oxygen and $\mathrm{pH}$. Deep-Sea Research, 41, 695-719.

HALL, P.O.J. (1984) Chemical fluxes at the sediment-seawater interface; In-situ investigations with benthic chambers. Ph. D. dissertation, University of Göteborg, Sweden, pp. 1-183.

HALl, P.O.J., L.G. ANDERSON, M.M. RuTGERS VAN DER LOEFF, B. SUNDBY and S.F.G. WESTERLUND (1989) Oxygen uptake kinetics in the benthic boundary layer. Limnology and Oceanography, 34, 734-746.

HALLBERG, R.O., L.E. BÅGANDER, A.-G. ENGVALL and F.A. SHIIPEL (1972) Method for studying geochemistry of sediment-water interface. Ambio, 1, 71-72.

HAMMOND, D.E., H.J. SIMPSON and G. MATHIEU (1977) Radon-222 distribution and transport across the sedimentwater interface in the Hudson River Estuary. Journal of Geophysical Research, 82, 3913-3920.

HELDER, W. and J.F. BAKKER (1985) Shipboard comparison of micro- and minielectrodes for measuring oxygen distribution in marine sediments. Limnology and Oceanography, 30, 1106-1109.

HENDRICKS, P.J. and G. RODENBUSH (1981) Interpretation of velocity profiles measured by freely sinking probes. Deep-Sea Research, 28 A, 1199-1213.

HINGA, K.R., J. MCN. SIEBURTH and G.R. HEATH (1979) The supply and use of organic material at the deep-sea floor. Journal of Marine Research, 37, 557-579.

HCETTEL, M. and G. GUST (1992) Solute release mechanisms from confined sediment cores in stirred benthic chambers and flume flows. Marine Ecology Progress Series, 82, 187-197.

IsAACs, J.D. and R.A. SCHWARTZLOZE (1975) Active animals of the deep-sea floor. Scientific American, 233, 84-91.

JAHNKE, R.A. and M.B. CHRISTIANSEN (1989) A free-vehicle benthic chamber instrument for sea floor studies. Deep-Sea Research, 36, 625-637.

KIRK, R.E., J.J. LANGFORD and R.B. WHITMARSH (1982) A three-component ocean-bottom seismograph for controlled source seismology. Marine Geophysical Researches, 5, 327-341.

KIRSTEN, O.H. and R.A. JAHNKE (1985) The lander: Recent developments in free vehicle platform design. Ocean 85 Conference Record, Marine Technology Society and Institute of Electrical and Electronics Engineers 12-14 November 1985, San Diego, California, USA.

Krom, M.D., P. DAVISON, H. ZhANG and W. DAvison (1994) High-resolution pore-water sampling with a gel sampler. Limnology and Oceanography, 39, 1967-1972.

LALLI, C.M., editor (1990) Enclosed Experimental Marine Ecosystems: A Review and Recommendations, Coastal and Estuarine Studies 37, Springer-Verlag.

LAMPITT, R.S. (1985) Evidence for the seasonal deposition of detritus to the deep-sea floor and its subsequent resuspension. Deep-Sea Research, 32, 885-897.

DE LANGE, G.J., R.E. CRANSTON, D.H. HYDES and D. BousT (1992) Extraction of pore water from marine sediments: A review of possible artefacts with pertinent examples from the North Atlantic. Marine Geology, 109, 53-76.

LINKE, P., E. SUESS, M. TORRES, V. MARTENS, W.D. RUGH, W.ZIEBIS and L.D. KULM (1994) In-situ measurements of fluid flow from cold seeps at active continental margins. Deep-Sea Research, 41, 721-739.

MORTENSEN, A.C. and R.E. LANGE (1976) Design consideration of wing stabilized free-fall vehicles. Deep-Sea Research, 23, 1231-1240.

NABATOV, V.N. and V.A. RAZZHIVIN (1986) The motion of a free falling probe in a shear flow. Oceanology, 26, 637-640.

NiELSEN, L.P., P.B. ChristensEn, N.P. REVSBeCH and J. SÆRENSEN (1990) Denitrification and photosynthesis in stream sediment studied with microsensor and whole-core techniques. Limnology and Oceanography, 35 , 1135-1144.

NIXON, W.S., C.A. OVIATT and S.S. HALE (1976) Nitrogen regeneration and the metabolism of coastal bottom communities. In: The Role of Terrestrial and Aquatic Organisms in Decomposition Processes, J.M. ANDERSON and A. MACFA YDEN, editors, Blackwell Science Publishers, pp. 269-283. 
OPD YKE, B.N., G. GUST and J.R. LEDWEL L (1987) Mass transfer from smooth alabaster surfaces in turbulent flows. Geophysical Research Letters, 14, 1131-1134.

PAMATMAT, M.M. and K. BANSE (1969) Oxygen consumption by the seabed. II. In situ measurements to a depth of $180 \mathrm{~m}$. Limnology and Oceanography, 14, 250-259.

Pamatmat, M.M. and D. Fenton (1968) An instrument for measuring subtidal benthic metabolism in situ. Limnology and Oceanography, 13, 537-540.

PFANNKUCHE, O. (1992) Organic carbon flux through the benthic community in the temperate abyssal Northeast Atlantic. In: Deep-Sea Food Chains and the Global Carbon Cycle, G. T. RowE and V. PARIENTE, editors, Kluwer Academic Publishers, pp. 183-198.

PFANNKLICHE, O. (1993) Benthic response to the sedimentation of particulate organic matter at the BIOTRANS station, $47^{\circ} \mathrm{N}, 20^{\circ} \mathrm{W}$. Deep-Sea Research $I I, 40,135-149$.

PHILIPS, G.R. (1980) The IOS acoustic command and monitoring system; Part 1 -operating principles and practices. Report 96, Institute of Oceanographic Sciences, UK.

REIMERS, C.E. (1987) An in-situ microprofiling instrument for measuring interfacial pore water gradients: methods and oxygen profiles from the North Pacific Ocean. Deep-Sea Research, 34, 2019-2035.

REMERS, C.E., R.A. JAHNKE and D.C. MCCORKLE (1992) Carbon fluxes and burial rates over the continental slope and rise off central California with implications for the global carbon cycle. Global Biogeochemical Cycles, 6, 199-224.

REvSBeCh, N.P., B.B. JøRGENSEN and T.H. BLACKBURN (1980a) Oxygen in the sea bottom measured with a microelectrode. Science, 207, 1355-1356.

REVSBECH, N.P., J. SøRENSEN, T.H. BLACKBURN and J.P. LOMHOLT (1980b) Distribution of oxygen in marine sediments measured with microelectrodes. Limnology and Oceanography, 25, 403-411.

REVSBECH, N.P. (1989) An oxygen microsensor with a guard cathode. Limnology and Oceanography, 34, 474-478.

RICE, A.L., M.H. THURSTON and B.J. BETT (1994) The IOSDL DEEPSEAS programme: photographic evidence for the presence and absence of a seasonal input of phytodetritus at contrasting abyssal sites in the northeastern Atlantic Ocean. Deep-Sea Research, 41, 1305-1320.

ROWE, G., G. BolAND, W. PHOEL, R. ANDERSON and P. BISCA YE (1995) Deep sea-floor respiration as an indication of lateral input of biogenic detritus from continental margins. Deep-Sea Research (in press).

RutGers VAN DER LoEFF, M.M., L.G. ANDERSON, P.O.J. HALL, À. IVERFELDT, A.B. Joserson, B. SUNDBY and S.F.G. WESTERLUND (1984) The asphyxiation technique: An approach to distinguishing between molecular diffusion and biologically mediated transport at the sediment-water interface. Limnology and Oceanography, 29, 675-686.

SANTSCHI, P.H., P. BOWER, U.P. NYFFELER, A. AZEVEDO and W.S. BROECKER (1983) Estimates of the resistance to chemical transport posed by the deep-sea boundary layer. Limnology and Oceanography, 28, 899-912.

SANTSCHI, P.H., P. HÖHENER, G. BenOIT and M. BuCHHOLTZ-TEN BRINK (1990) Chemical processes at the sediment-water interface. Marine Chemistry, 30, 269-315.

SANTSCHI, P.H., U.P. NYFFELER, P. O'HARA, M. BUCHHOLTZ and W.S. BROECKER (1984) Radiotracer uptake on the sea floor: results from the MANOP chamber deployments in the eastern Pacific. Deep-Sea Research, 31, $451-468$.

SAYLE, F.L. (1979) The composition and diagenesis of interstitial solutions: 1. Fluxes across the seawater-sediment interface in the Atlantic Ocean. Geochimica et Cosmochimica Acta, 43, 527-545.

SAYLES, F.L. and W.H. DICKINSON (1991) The ROLAI'D lander: a benthic lander for the study of exchange across the sediment-water interface. Deep-Sea Research, 38. 505-529.

SMITH, K.L. JR. (1978) Benthic community respiration in the NW. Atlantic Ocean: In situ measurements from 40 to $5200 \mathrm{~m}$. Marine Biology, 47, 337-347.

SMITH, K.L. JR. (1987) Food energy supply and demand: A discrepancy between particulate organic carbon flux and sediment community oxygen consumption in the deep ocean. Limnology and Oceanography, 32, 201220.

SMITH, K.L. JR. and R.J. BALDWIN (1983) Deep-sea respirometry: In situ techniques. In: Polarographic Oxygen Sensors, Gnaiger and Forstner, editors, Springer-Verlag, Berlin, pp. 298-319.

SMITH, K.L. JR., C.H. ClifforD, A.H. Eliason, B. WALDEN, G.T. Rowe and J.M. TEAL (1976) A free vehicle for measuring benthic community metabolism. Limnology and Oceanography, 21, 164-170.

SMITH, K.L. JR. and J.M. TEAL (1973) Deep-sea benthic community respiration: An in-situ study at 1850 meters. Science, 179, 282-283. 
SMITH, K.L. JR., G.A. WHITE and M.B.LAVER (1979) Oxygen uptake and nutrient exchange of sediments measured in-situ using a free vehicle grab respirometer. Deep-Sea Research, 26, 337-346.

SPENCER, R., P.R. FoDEN and J.M. VASSIE (1994) Development of a Multi-Year Deep Sea Bottom Pressure Recorder. In: Electronic Engineering in Oceanography, IEE Conferance Publication, 394.

STACHIW, J.D., R.P. JOHNSON and R.R. KURKCHUBASCHE (1993) Ceramics show promise in deep submergence housings. Sea Technology, 12, 35-41.

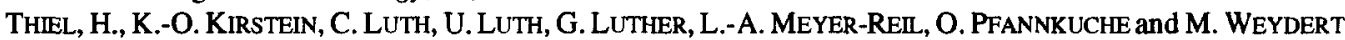
(1994) Scientific requirements for an abyssal benthic laboratory. Journal of Marine Systems, 4, 421-439.

THOMSEN, L., G. GRAF, V. MARTENS and E. STEEN (1994) An instrument for sampling water from the benthic boundary layer. Continental Shelf Research, 14, 871-882.

VANGRIESHEIM, A. and A. KHRIPOUNOFF (1990) Near-bottom particle concentration and flux: temporal variations observed with sediment traps and nephelometer on the Meriadzek Terrace, Bay of Biscay. Progress in Oceanography, 24, 103-116.

WEHRLI, B., C. DINKEL and N. URBAN (1994) Benthic flux chamber measurements of boundary layer mineralization in an eutrophic lake. Aquatic Sciences, (submitted).

WEISS, R.F., O.H. KIRSTEN and R. ACKERMAN (1977) Free vehicle instrumentation for the in-situ measurements of processes controlling the formation of deep-sea ferromanganese nodules. Oceans'77 Conference Record, 44D, Marine Technology Society and Institute of Electrical and Electronics Engineers.

Van DEN VlehBeRT, H.H. and N.F. DE ROOIJ (1988) ISFET, Ion Sensitive Field Effect Transistor for pH measurements. Design, fabrication and characterisation. Analysis, 16, 110-119.

ZerTzsChEL, B. and J.M. DAVIS (1978) Benthic growth chambers. Rapport P.-V. Réunion Conseil International pour Exploration de la Mer, 173, 31-42. 